\title{
The impact of investment incentives: evidence from UK corporation tax returns
}

\author{
Giorgia Maffini* Jing Xing ${ }^{\dagger}$ Michael P. Devereux ${ }^{\ddagger}$
}

\begin{abstract}
Using UK corporation tax returns, we provide evidence on the effects of accelerated depreciation allowances on investment, exploiting exogenous changes in the qualifying thresholds for first-year depreciation allowances (FYAs) in 2004. The investment rate of qualifying companies increased by $2.1-2.5$ percentage points relative to those that did not qualify. We exploit variation in the timing of tax payments to show that this effect is primarily due to the change in the cost of capital, rather than a relaxation of financial constraints. Discontinuity at notches in the cost of capital at the qualifying thresholds does not affect our results.
\end{abstract}

Key words: investment, corporate tax, depreciation allowances, SMEs. JEL category: E22; H25; O16.

Acknowledgement: This work contains statistical data from Her Majesty's Revenue and Customs (HMRC) which is Crown Copyright. The research datasets used may not exactly reproduce HMRC aggregates. The use of HMRC statistical data in this work does not imply the endorsement of HMRC in relation to the interpretation or analysis of the information. We thank Daniele Bega, Manpreet Khera, Lucy Nicholson, Yee-Wan Yan and all the staff at the HMRC Datalab for their excellent support. We thank Katarzyna Habu for carefully organizing the FAME ownership data, Wiji Arulampalam, Steve Bond, Mihir Desai, Dhammika Dharmapala, Judith Freedman, Irem Guceri, Chris Heady, Shafik Hebous, Kelvin Law, Andreas Oestreicher, Eric Ohrn, Beatrice Parrish, Martin Ruf, Joel Slemrod, Malanie Whent, the HMRC KAI and HMT capital allowances teams, seminar participants at the NBER summer institute, the Taxing Multinational Firms ZEW conference, the Research Colloquium at the University of Goettingen, the Economics Dept. Seminar Series (Ancona), the EIASM workshop (Muenster), the 2014 IIPF conference (Lugano), the HMRC Economics Seminars, the Empirical Tax Workshop (Australian National University), the Economics Dept. Seminars (University of Strathclyde), the 2015 ZEW Public Finance conference, the 2015 OUCBT Annual Symposium, the 2015 Public Economics UK seminar (Exeter), the Economics Seminars at the Imperial College (London), Queen Mary University (London), the Melbourne Business School, the 2017 HMRC/OUCBT workshop (Oxford), and the IMF Fiscal Affairs Department seminar (Washington) for useful comments. Michael Devereux and Jing Xing gratefully acknowledge financial support from the ESRC (ES/L000016/1). Giorgia Maffini gratefully acknowledges financial support from the Leverhulme Trust (ECF-2013-323) and the University of Oxford John Fell OUP Research Fund.

\footnotetext{
*Oxford University Centre for Business Taxation, Saïd Business School, University of Oxford; Dondena Centre for Research on Social Dynamics and Public Policy, Bocconi University; and the OECD. Email: giorgia.maffini@oecd.org.

†Antai College of Economics and Management, Shanghai Jiao Tong University. Email: jing.xing@sjtu.edu.cn.

${ }_{\ddagger}^{\ddagger}$ Oxford University Centre for Business Taxation, Saïd Business School Business School, University of Oxford. Email: michael.devereux@sbs.ox.ac.uk.
} 


\section{Introduction}

Higher investment rates and hence a higher level of the capital stock in the economy could increase productivity and national welfare. A relevant policy issue for any government is then how to stimulate firms' investment effectively. Many OECD countries have frequently used the corporation tax system to encourage investment. For example, more generous deductions for capital expenditure increase the present value of depreciation allowances and consequently reduce the user cost of capital, which in turn increases the incentive to invest (Jorgenson, 1963; Hall and Jorgenson, 1967; Hayashi, 1982; and Summers, 1981). In the United States, accelerated first-year investment allowances for equipment (known as the bonus depreciation deduction) were available between 2002 and 2004 and then again, between 2008 and 2017 after the onset of the global financial crisis. In the United Kingdom, before the fiscal year 2008/09, accelerated first-year capital allowances (FYAs) for investment in plant and machinery were available to small and medium-sized enterprises (SMEs) at a rate of 40 per cent compared to the standard rate of 25 per cent available to larger companies.

Many have advocated the use of accelerated depreciation to stimulate business spending on plant and equipment (for example, Feldstein, 2006). In this study, we examine the impact of a change to the tax depreciation schedule for a group of companies in the United Kingdom that occurred due to an exogenous change in the qualifying threshold for FYAs. Specifically, companies could qualify as SMEs and hence claim FYAs if they were below two of three thresholds based on turnover, total assets, and number of employees. ${ }^{1}$ In 2004, implementing a Recommendation of the European Commission on the definition of SMEs, the UK increased the turnover and total assets thresholds more than twofold. We exploit this quasi-experimental setting where our treatment group is composed of companies that did not qualify before 2004 but became qualified under the new thresholds since 2004. Companies which never qualified for FYAs throughout our sample period constitute the control group. We compare the investment patterns before and after 2004 across the two groups using a difference-indifferences approach. As the changes in the qualifying thresholds for FYAs are not related to aggregate economic conditions or firm-level unobserved shocks, our estimation results are unlikely to suffer from endogeneity biases.

To conduct our empirical analysis, we use confidential UK corporation tax returns matched with companies' financial statements. From tax returns, we obtain precise information on companies' qualified investment in plant and machinery, which is generally not available in accounting data, especially for small, privately-held companies. Tax returns also allow us to control precisely for companies' marginal tax rates, which can differ substantially across UK companies due to the graduated marginal tax rate structure described below. Moreover, from corporation tax returns we observe the

\footnotetext{
${ }^{1}$ Turnover is equivalent to sales. We use turnover as it is the terminology used in both the European Commission's definition for an SME and the UK corporate tax return (line 1).
} 
timing of corporate tax payments, which provides us with a unique opportunity to test whether there is a cash flow effect arising from a lower tax payment.

We find a substantial positive effect of more generous depreciation allowances on firms' investment. Relative to the control group, FYAs raised the investment rate in eligible assets of newly qualified companies by between 2.1 and 2.5 percentage points within 3 years of the change in the definition of SMEs. The implied elasticity of investment with respect to the net-of-tax cost of a unit investment is between 8.3 and 9.9. Our findings reinforce results in existing studies on the effectiveness of accelerated depreciation allowances on stimulating private investment (Cummins et al., 1994; House and Shapiro, 2008; Edgerton, 2010; Zwick and Mahon, 2017; and Ohrn, 2018a, b). We show that firms do not react immediately, which points to the existence of adjustment costs. However, the adjustment costs are low as firms do increase investment relatively quickly within a maximum of between 12 to 18 months.

To investigate whether firms manipulate their size indicators to qualify as SMEs, we test for the salience of FYAs provisions in the UK by examing whether firms bunched at the notches in the cost of capital created by the existence of qualifying thresholds. There is some evidence of discontinuity in the distribution of size indicators around the qualifying turnover and total assets thresholds. Nevertheless, we show that excluding companies close to these qualifying thresholds does not affect our benchmark results, implying that FYAs are effective in stimulating investment for a wider group of companies and not only for those able to manipulate their size indicators.

FYAs can stimulate investment through two channels: by reducing the user cost of capital, and by relaxing companies' financial constraints. Regarding the cash flow effects of the bonus depreciation, Edgerton (2010) finds that firms with more cash flow responded more to higher capital allowances. In contrast, Zwick and Mahon (2017) find that cash-constrained firms reacted more to bonus depreciation deductions. To test the cash flow effect, most studies use conventional approaches such as splitting the sample based on measures of cash flow or firm size. Nonetheless, Farre-Mensa and Ljungqvist (2015) show that conventional measures of financial status may not reflect accurately whether a firm is financially constrained. We use an innovative method to test the cash flow effect by using the variation in the timing of the corporate income tax payments. If cash flow effects were important, investment increases should be delayed for firms that pay taxes in arrears as cash flows generated by the newly available FYAs will arrive up to 9 months after policy implementation. We find that the effect of FYAs is more likely due to changes in the cost of capital than due to changes in firms' cash flow. This conclusion is reinforced when we use conventional measures to infer firms' financial status. Therefore, our results demonstrate that accelerated depreciation allowances can effectively stimulate investment of SMEs during non-recession periods, and more generally when companies are not financially constrained, by lowering the user cost of capital. Another implication is that accelerated depreciation allowances can also be 
an effective policy tool to stimulate investment of larger firms, which are less likely to be financially constrained (Hadlock and Pierce, 2010).

The availability of tax returns allows us to analyze how FYAs affect the investment of smaller, private companies. ${ }^{2}$ This would not be possible using publicly available databases, such as Compustat as smaller companies are less likely to be included. It is of policy interest to analyze the behavior of SMEs, which constitute the majority of firms in many economies. For example, depending on the definition, SMEs account for between 95 and 99 percent of total UK companies, and more than half of total employment and sales. ${ }^{3}$ The effectiveness of tax incentives could also be different for smaller private companies than for large public companies. For example, smaller and private companies could be more financially constrained and a complex tax code may be less salient for them. As far as we know, ours is one of the few studies which specifically analyze the effectiveness of investment tax incentives for small or mediumsized, private companies.

The rest of our paper is structured as follows. Section 2 illustrate how capital allowances work in the United Kingdom. Section 3 explains our identification strategy and how we construct our sample for empirical analysis. Section 4 provides our benchmark results. We analyze whether firms bunched below the qualifying thresholds to enjoy the tax benefits in Section 5. In Section 6, we test the cash flow effect. Section 7 concludes.

\section{The UK system for capital allowances}

Until fiscal year $2007 / 08,{ }^{4}$ the basic structure of the UK system of depreciation allowances for plant and machinery, also called capital allowances, consisted mainly of two types of allowances: writing-down allowances (WDAs) for the life of the asset applied at a rate of 25 per cent on a reducing balance basis and FYAs available only to SMEs at a rate of 40\% (Tiley and Loutzenhiser, 2013). WDAs and FYAs could be claimed only for expenditures in plant and machinery. ${ }^{5}$ FYAs for plant and machinery were introduced in 1997 and made permanent in 1998. SMEs could generally claim 40 per cent FYAs on their investment, ${ }^{6}$ although small but not medium firms could temporarily claim FYAs of 50 per cent in some years (Table 1).

There are different definitions of small and medium sized businesses in UK cor-

\footnotetext{
${ }^{2}$ Our data does not cover unincorporated small private enterprises as they are not subject to the corporate income tax.

${ }^{3}$ Business Population Estimate for the UK and Regions (2017).

${ }^{4}$ In the UK, the fiscal year for corporate income tax purposes runs from 1 April to 31 March.

${ }^{5}$ The legislation on capital allowances is contained within the Capital Allowances Act (CAA) 2001. Spending on certain assets such as cars, long-life assets and plant or machinery for leasing did not qualify. CAA 2001 provides lists of exclusions (CAA01/S21\& 22) and included items (CAA01/S23). See also Standing Committee on the Bill (2004).

${ }^{6}$ If FYAs were claimed, WDAs could only be claimed starting from the second year of the life of the same assets.
} 
porate and tax law but the relevant one for claiming FYAs is derived from EU law (Freedman, 2003). Table 2 sets out the definition. To be classified as small or medium for claiming FYAs, a company needed to satisfy two of three criteria, encompassing turnover, total assets and the number of employees in the current and preceding financial year. At the time when FYAs were introduced, the threshold for qualifying as an SME was £11.2 million for turnover, £5.6 million for total assets, and 250 for the number of employees.

In May 2003, the European Commission adopted a Recommendation concerning the definition of SMEs whereby the financial ceilings on turnover and total assets were substantially increased with respect to the 1996 definition. ${ }^{7}$ The new threshold became $£ 22.8$ million for turnover, and £11.4 million for total assets. On 10 December 2003, the UK Chancellor of the Exchequer announced the implementation of the new European definition, increasing the thresholds for defining small and medium-sized businesses to the maximum allowed under European Union regulations. This meant that the upper limits for qualifying as an SME for FYA purposes were more than doubled for the turnover and total assets thresholds (Table 2, bottom panel). On that occasion, it was announced that the change in qualifying thresholds would affect any qualifying expenditure undertaken in financial years ending on or after 30 January, 2004. That is, for newly qualified firms, the FYA rate of 40 per cent applied to qualifying expenditures undertaken even before the announcement, as long as the end of the financial year was on or after January 30, 2004. The same thresholds were relevant for claiming SMEs research and development $(\mathrm{R} \& \mathrm{D})$ tax credits. A subsequent change in the thresholds in 2008 has been studied by Guceri and Liu (2018), who found a significant effect of the tax credits on R\&D spending. For our purposes the issue is whether the availability of R\&D tax credits may affect investment in plant and machinery. Although there is the possibility of complementarity between these two types of spending, the most likely effect of the R\&D tax credits on investment in plant and machinery is that such investment would be relabelled as R\&D, thereby being eligible for much more generous tax treatment. This would bias downwards any effects we find of FYAs on investment in plant and machinery. The lower thresholds for qualifying as small (not medium) enterprises were also relevant for audit exemption.

Although FYAs were introduced in 1998 as a permanent policy, the Chancellor unexpectedly announced a large overhaul of the capital allowances system on 21 March 2007 as part of the 2008/09 Budget. The overhaul took effect from the following fiscal year and this entailed the repeal of FYAs for plant and machinery expenditures incurred on or after 1 April 2008. From fiscal year 2008/09, the rate of WDAs was cut to 20 per cent and FYAs were replaced by the Annual Investment Allowance, a $£ 50,000$ allowance available to all businesses (Maffini, 2013).

\footnotetext{
${ }^{7}$ The European Commission Recommendation of 6 May 2003 replaced the previous Commission Recommendation of 3 April 1996 on which the old UK definition of small and medium-sized enterprises was based.
} 
The corporate statutory tax rate also changed over time (Table 3 ). The standard rate of corporation tax was cut from 33 to 30 per cent in 1999 and to 28 per cent in 2008. The UK system levied a reduced rate (known as the small company rate, SCR) on profits under $£ 300,000$. The SCR was reduced from 21 per cent to 20 per cent in 1999/00, to 19 per cent in 2002/03 and then increased again in 2007/08 to 20 per cent and to 21 per cent in 2008/09. For firms with profits between $£ 300,000$ and $£ 1,500,000$, a system of marginal relief operated, which raised the marginal rate to over 32 per cent in most years. Finally, a starting rate of between zero and 10 per cent applied to profits below $£ 10,000$ between 2001/02 and 2005/06, and another, higher, marginal rate was applied to the remaining profit below $£ 50,000$. This complex corporation tax schedule leads to rich cross-sectional and time-series variation in companies' marginal tax rates.

\section{Identification strategy and data}

\subsection{Identification strategy}

The changes in the turnover and total assets thresholds for claiming FYAs detailed above imply that some firms which did not qualify for the scheme before the reform subsequently became qualified. We identify a treatment group of firms which did not qualify for FYAs prior to 2004 but became qualified for expenditures undertaken in financial years ending from January 30, 2004 onwards. Large firms which never qualified for FYAs constitute our main control group. ${ }^{8}$

For our benchmark analysis, we allocate firms into the treatment and control groups on the basis of turnover only, since data on turnover is available for most firms. More specifically, we allocate companies to the treatment group if their turnover was above $£ 11.2$ million (the old threshold) in each year before 2004 and below $£ 22.8$ million (the new threshold) in each year after the reform. We allocate firms into the control group if their turnover was above $£ 11.2$ million in each year before the reform and above $£ 22.8$ million in each year after the reform. As a stricter classification, we use both turnover and total assets to determine whether or not a firm is treated. As we show below, using turnover and total assets jointly significantly reduces the sample size. A smaller sample would be a challenge when estimating the adjustment costs and the cash flow effect, which requires us to split the sample in various ways.

To identify the treatment effect, we estimate a difference-in-differences model as

\footnotetext{
${ }^{8}$ We do not use always medium-sized companies as the control group because there is no parallel trend of investment between them and the treated group. We do not use always small-sized companies as the control group because the rate of FYAs for them changed multiple times during the sample period.
} 
Equation (1):

$$
\frac{I_{i, t}}{K_{i, t-1}}=\alpha+\beta_{1} d_{i, t}^{R}+\beta_{2} d_{i}^{T}+\beta_{3} d_{i, t}^{R} \times d_{i}^{T}+\gamma \bar{X}_{i, t}^{\prime}+\zeta_{t}+\eta_{i}+\varepsilon_{i, t}
$$

where $I_{i, t} / K_{i, t-1}$ is the gross investment rate, calculated as the ratio of current capital expenditures in plant and machinery to fixed assets at the beginning of the period. $d_{i, t}^{R}$ is a dummy equal to one for financial year ending on or after 30 January 2004, when the new thresholds for qualifying for FYAs applied. $d_{i}^{T}$ is a dummy equal to one for the treatment group. The parameter of interest in the difference-in-difference analysis is the coefficient $\beta_{3}$ on the interactive term $d_{i, t}^{R} \times d_{i}^{T}$. It captures the effect of the treatment in our quasi-natural experiment. $\bar{X}_{i, t}^{\prime}$ is a vector of firm characteristics explained below. $\zeta_{t}$ captures the time effects and $\eta_{i}$ denotes firm-specific fixed effects. $\varepsilon_{i, t}$ is the error term.

Capital allowances may in principle affect investment via two main channels by lowering the cost of capital, and for cash constrained firms, by increasing the availability of cash due to reduced tax liabilities. Before 2004, firms in the treatment groups could claim only WDAs for expenditure on plant and machinery at the rate of 25 per cent. From 2004, treated firms could depreciate qualified expenditures at 40 per cent in the first year, and thereafter at a declining balance rate of 25 per cent. As shown in Appendix $\mathrm{A}$, the present value of depreciation allowances, $A$, can be written as:

$$
A=\tau f+\frac{\tau d(1-f)}{(r+d)}
$$

where $\tau$ is the marginal corporate income tax rate, $r$ is the discount rate, $f$ is the rate of tax depreciation in the first year of investment, and $d$ is the rate of tax depreciation in subsequent years. For treated firms, $f=d=0.25$ before they qualified as SMEs. $f=0.4$ and $d=0.25$ for treated firms once they became qualified for FYAs. If we assume that the discount rate is 7\%, ${ }^{9}$ our calculation in Appendix A shows that FYAs increase the present value of capital allowances for qualifying expenditures by around $3.9 \%$. Assuming that the marginal corporate income tax rate is $32.75 \%,{ }^{10}$ this means a $1.5 \%$ reduction in the net-of-tax cost of a unit investment, $1-A$. According to the neoclassical investment theory (Hall and Jorgenson, 1967), a lower user cost of capital due to the increase in $A$ should lead to a higher level of capital stock in the long run and consequently to an increase in the investment rate in the short run. In addition, if a firm is financially constrained, more generous capital allowances can relieve financial constraints by lowering the tax liability and further increase the investment of the firm. For these reasons, we expect the treatment effect, $\beta_{3}$, to be positive.

In our regressions, we also control for a vector of firm characteristics $\left(\bar{X}_{i, t}^{\prime}\right)$, which

\footnotetext{
${ }^{9}$ This assumption about the discount rate is similar to that used by Zwick and Mahon (2017) and is close to the average interest rate for firms in our sample.

${ }^{10}$ This is the maximum marginal tax rate for UK companies during our sample period (Table 3).
} 
includes the growth rate of turnover, the lagged profitability, the marginal corporate tax rate and the growth rate of total assets. The neoclassical investment theory predicts a direct link between output and capital stock accumulation, thus we control for the growth rate of turnover. As slow-growing or shrinking companies may self-select into the treatment group, we control for the growth rate of total assets in addition to turnover growth. We control for the lagged profitability because more profitable companies are likely to invest more. The statutory corporate income tax rate varies across firms and over time, which would affect the user cost of capital. Thus, we control for firms' marginal tax rate to isolate the effect of FYAs.

\subsection{Data}

We merge two datasets to construct our sample. The first is the universe of UK corporation tax returns (CT600 forms) for the period 2001/02 to 2008/09 available on a confidential basis in the Datalab of the UK tax authority (Her Majesty's Revenue and Customs - HMRC). This contains detailed information on firms' turnover, capital allowances claimed, taxable income and hence on the applicable marginal statutory corporation tax rate, and on the size of the corporate tax liability which allows us to identify whether company pays corporation tax in arrears or in quarterly installments. Additionally, tax return data provide precise information on firms' investment in plant and machinery. This is a major advantage of tax return data, since other data sources for UK firms either do not report investment, or do not break down investment between equipment and buildings. The second dataset is FAME (Bureau Van DijK) which collects balance sheet and income statement information for UK companies. We use FAME to obtain information on companies' total assets, fixed assets and cash flows.

Table B1 in Appendix B explains in detail how we construct the sample. We restrict the sample to the fiscal years $2002 / 03$ to $2006 / 07$. Our dependent variable $\left(I_{i, t} / K_{i, t-1}\right)$ and several control variables require one lag and therefore, we lose fiscal year 2001/02 which is the first available year in the HMRC corporate tax returns and the FAME data we use. In March 2007, the UK Chancellor announced a large overhaul of capital allowances to be phased in from fiscal year 2008/09. ${ }^{11}$ Some companies may have reacted to this latter reform as early as in fiscal year 2007/2008 and hence, we exclude fiscal years from 2007/08 onwards to isolate the effects of FYAs. Excluding the later years can also help us avoid confounding effects from the 2007-2008 financial crisis. To exclude outliers, we drop observations in the top percentile of the distribution of investment rate and of the growth rate of turnover. We construct a balanced panel which requires each firm to have non-missing observations throughout the sample period (2002/03 to 2006/07). The final sample consists of 17,365 firm-year observations

\footnotetext{
${ }^{11}$ The UK government announced the Anual Investment Allowances on 21 March, 2007, for simplification purposes in particular for SMEs. The AIA allows for immediate expense of investment below certain thresholds.
} 
for 3,473 firms. In our benchmark sample, 906 firms belong to the treatment group and 2,567 firms to the control group.

Table 4 compares the two groups of firms in terms of their turnover, growth rate of turnover, total assets, growth rate of total assets, profitability, marginal tax rate, investment rate, and cash flow. ${ }^{12}$ As expected, firms in the treatment group are smaller on average in terms of turnover and total assets than those in the control group. While the average growth rate of turnover of treated firms is negative, it is positive for the control group. A similar pattern is found for the growth rate of total assets. This raises the possibility that some firms are in the treatment group because their turnover or total assets shrunk over time. Consequently, we control for the growth rate of turnover and that of total assets to avoid any bias caused by shrinking firms. Other variables such as profitability are more comparable between the two groups.

We further compare the investment rate of the treated group before and after the reform. Table 5 shows that for the treated, the average investment rate for the periods after the reform (0.192) is significantly higher than that for the periods before the reform (0.169). The t-test shows that the null hypothesis of equal investment rates is rejected at the 5 per cent level. Firms in the control group have a higher average gross investment rate both before and after the reform. However, for firms in the control group, we cannot reject the null hypothesis that their average investment rate after the reform (0.205) equals that before the reform (0.203).

\section{Results}

\subsection{Benchmark analysis}

To illustrate the changes in treated firms' investment behavior since the reform, we plot the difference in the investment rate between the treated and the control groups from 2-years prior to the reform to 2-years after the reform in Figure 1. We control for firm-level characteristics while estimating differences in the investment rate. ${ }^{13}$ Each dot in Figure 1 represents the point estimate while the vertical bar represents the 95\% confidence interval. Figure 1 illustrates that before the reform, there is no significant difference in the investment rate between the treated and the control groups after controlling for observed firm-level characteristics. This suggests that the parallel trend assumption holds. However, the investment rate of the treated firms increased significantly in the year when they became qualified for FYAs. ${ }^{14}$ The gap between the two groups persists over the next two years.

\footnotetext{
${ }^{12}$ See Table B2 in Appendix B for the definition of the variables.

${ }^{13}$ See Figure 1 for more details.

${ }^{14}$ The point estimate for the difference in the investment rate between the treated and the control groups in the year of qualification is 0.029 , which is statistically significantly different from 0 at the 10 per cent level.
} 
We estimate Equation (1) and report the results in Table 6. Throughout Table 6, we control for firm-specific fixed effects, ${ }^{15}$ and cluster the standard errors by industry. This approach should deal with possible within-industry serial correlation in the error terms. In unreported regressions, we also bootstrap the standard errors by industry. This alternative way of calculating the standard errors delivers no difference with respect to our key results. Hence, we report results when the standard errors are clustered by industry for the rest of the paper. Column (1) shows the benchmark estimation result when we do not control for any firm characteristics or business cycle effects. On average, there is no evidence of a common increase in the investment rate after the policy change for both groups, as the estimated coefficient on the dummy $d_{i, t}^{R}$ is not statistically different from zero. The coefficient on $d_{i}^{T}$ is not identified as the treatment status is time invariant. The estimate of $\beta_{3}$ is positive and significant at the 10 per cent level. Column 1 suggests that after the reform, the investment rate of the treated group increased on average by 2.1 percentage points relative to that of the control group.

Some firms could have entered the treatment group because they were shrinking in size, others because they manipulated their size indicators to qualify for FYAs. The former type of firms is likely to have a lower propensity to invest, which could bias our estimate of $\beta_{3}$ downward; while the latter type is likely to have a higher propensity to invest and this may bias our estimate of $\beta_{3}$ upward. In column (2), we control for the growth rate of turnover to address these concerns. We observe only a slight increase in the size of the estimated coefficient $\beta_{3}$ in column (2). In Section 5, we will further address the possibility of firms manipulating their size indicators.

When capital goods are in high demand, their price could increase which may drive up the user cost of capital. This potentially reduces the effect of more generous capital allowances on investment. In column (3), we add a set of year dummies to control for common business cycle effects. In this column, the estimated coefficient $\beta_{3}$ remains positive and significant at the 10 per cent level. In column (4) we employ a full set of sector-year dummies, which controls for the cross-sector and over-time variation in the price component of the user cost of capital. The estimated treatment effect is now positive and statistically significant at the 5 per cent level. In both columns (3) and (4), the magnitude of the point estimate for $\beta_{3}$ is close to that in column (1). As the magnitude of the estimated treatment effect varies very little across different specifications, this suggests that our results are unlikely to be confounded by the price factor.

In columns (5) and (6), we control for additional observable characteristics of the companies. We control for the firm-specific marginal corporate income tax rate - a higher marginal tax rate leads to a higher the user cost of capital and consequently, a lower investment rate, all else equal. The sign of the coefficient on the marginal

\footnotetext{
${ }^{15}$ We find similar results when estimating Equation (1) using the Ordinary Least Squares estimator.
} 
tax rate is negative and the point estimate is significant, which is consistent with the neoclassical investment theory (for example, Hall and Jorgenson, 1967). We also control for the firms' profitability in the previous year. The estimated coefficient on the lagged profitability is positive and highly significant, suggesting that more profitable firms invest more. We further control for the growth rate of total assets and not surprisingly, firms which grow faster also invest more. While we control for a common set of year dummies in column (5), we control for sector-year dummies in column (6). In these two columns with additional control variables, we continue to find a positive and significant treatment effect. The point estimate for $\beta_{3}$ is 0.025 in both columns, which is rather close to estimates in previous columns.

Bertrand et al. (2004) point out that serial correlations can lead to overrejection of the null hypothesis of no effect in Difference-in-Differences estimations. As a robustness check, we conduct randomization inference. Appendix $\mathrm{C}$ provides more details on this procedure. Dealing with potential serial correlation in this way yields similar results as in Table 6. For example, based on the specification in column (5), we obtain a p-value of 0.014 for the point estimate of $\beta_{3}$, which indicates that estimated treatment effect is statistically significant at the 5 per cent level.

In Table 6, we estimate Equation (1) using a balanced sample. In unreported exercises, we construct an unbalanced sample where firms only need to have two years before and after the treatment. The sample size increases from 17,365 observations to 20,390 observations. Most importantly, we obtain similar results using the larger, unbalanced panel. We conduct the rest of our analysis based on the balanced panel. As we do not have firm entry and exit using the balanced panel, we need not to be concerned about potential contamination due to changes in the sample composition.

In summary, the results in Table 6 show that lowering the qualifying threshold for FYAs leads to an increase in the investment rate by around 2.1-2.5 percentage points among treated firms. The average investment rate for the treated firms before the reform is 0.17 . Thus, the investment rate increases by $12.4 \%-14.8 \%$. Assuming the marginal corporate income tax rate is $32.75 \%$ and the discount rate is $7 \%$, FYAs reduce the net-of-tax cost of a unit investment, 1-A, by around 1.5\% (Appendix A). Therefore, the implied elasticity of investment with respect to the net-of-tax cost of a unit investment is about 8.3-9.9. Using a similar specification to study the effects of the Domestic Production Activities Deduction (DPAD), Ohrn (2018a) calculates this elasticity to be around 6.5. Thus, our estimate is slightly larger.

Other studies estimate the elasticity of capital expenditures with respect to the net-of-tax cost of a unit investment. ${ }^{16}$ For example, House and Shapiro (2008) find that the elasticity of capital expenditures with respect to changes in the net-of-tax rate due to the US bonus depreciation is between 6 and 14. Zwick and Mahon (2017)

\footnotetext{
${ }^{16}$ Other studies (for example, Auerbach and Hassett, 1992; Cummins, Hassett and Hubbard, 1994; Chirinko, Fazzari and Meyer, 1999; Desai and Goolsbee, 2004; Bond and Xing, 2015) estimate the elasticity of capital accumulation with respect to the user cost of capital.
} 
estimate this elasticity to be around 7. Using plant-level data, Ohrn (2018b) obtains a larger elasticity of around 10. To make a more direct comparison with these studies, we estimate the treatment effect while using the natural logarithm of the qualified capital expenditures as the dependent variable. As the dependent variable is no longer a growth variable, we correspondingly control for the level of turnover and firm size (both in logs) on the right-hand side. We continue to control for the lagged profitability and the marginal tax rate in this elasticity estimation. Table 7 reports the estimation results using this specification. The point estimate on $d_{i, t}^{R} \times d_{i}^{T}$ is 0.161 when we control for common business cycles (column 1, Table 7), and is essentially the same when we control for sector-specific business cycle effects (column 2, Table 7). This translates into an elasticity of capital expenditures with respect to the net-of-tax cost of a unit investment around 10.7, which is close to the estimate in Ohrn (2018b) and is at the upper end of the range of estimates in this literature.

There are at least two possible explanations for the larger elasticity we find. First, the changes in the qualifying thresholds for FYAs were implemented in the fiscal year 2004/2005 and our sample covers until 2006/2007. During this post-reform period, the UK economy experienced relatively high growth. In contrast, the US bonus depreciation was introduced as a temporary and counter-cyclical policy during a period of economic downturn. It is possible that the effects of depreciation allowances are larger in economic good times as investment demand is stronger. Secondly, although FYAs were made permanent in 1998, the status of being an SME may vary as a firm grows. As a result, firms may respond to FYAs strongly if they believe their size status would change shortly. Again, this is a likely scenario during the post-reform period when the UK economy was expanding.

We also investigate whether higher FYAs affected the extensive margin of investment. However, only around $7 \%$ of observations in our sample report zero investment. In unreported exercises, we estimate the marginal effects using different estimators (Probit, Logit, and a linear probability model), where the dependent variable is a dummy that equals 1 if a firm made non-zero investment in plant and machinery in a particular year, and 0 otherwise. Unsurprisingly, we do not find any significant effect of FYAs at the extensive margin since the majority of firms report positive investment throughout our sample period. Thus, the positive impact on investment mainly comes from the intensive margin.

\subsection{Adjustment costs}

One relevant question for policy makers is how quickly the tax incentives could become effective. Answers to this question depend on various factors, including the magnitude of costs associated with adjustments of the capital stock. Our dataset provides a unique variation to test the existence and the magnitude of adjustment costs, since companies in our sample have different end dates for their reporting year. The new thresholds for 
FYAs were announced in December 2003 and became effective on January 30, 2004. Companies in our treated group with accounts ending earlier in 2004 (for example, in February and March) had less time to adjust their investment plans in the first qualifying year (Year 1) than those with accounts ending later in 2004. For example, firms with year-end in July 2004 had eight months before the end of their Year 1 to adjust investment in this year and in contrast, firms with year-end on January 31, 2004 only had a little over one month before the end of qualifying Year 1 to adjust their investment plans for that year.

Consequently, if adjustment costs are large, treated companies with financial accounts ending earlier in 2004 would be more likely to increase their investment in Year 2 rather than in Year 1. In comparison, treated companies with accounts ending later in 2004 would be more likely to increase their investment in Year 1, if adjustment costs are not substantial. To test this, in Table 8, we split the treated group between firms with accounts ending between January and June (column (1)) and those between July and December (column (2)). The results show that firms increased investment with a time lag: the first group only increased investment in Years 2 and 3 while the second group increased investment in Year 1. In columns (3) and (4) we increase the sample size by relaxing the requirement of having a balanced panel: companies in this sample only need to appear two years before the reform and two years after that. The pattern of the results is similar, although we now observe a statistically significant increase in investment rate for the first group of treated firms in Year 2.

It is worth noting that if firms with accounts ending between January and June fully anticipated the UK reform after the European Commission's May announcement, they would have the opportunity to postpone investment from the previous financial year to Year 1. In this case, we should observe an increase in these firms' investment in Year 1 even with the presence of substantial adjustment costs. The fact that we do not find any significant change in the investment rate for this group of firms in Year 1 also indicates that the UK reform and its timing were unexpected.

Taken together, our analysis shows that companies did not react immediately to the availability of more generous FYAs, consistent with the presence of adjustment costs. Nonetheless, companies reacted relatively quickly, within 12 to 18 months from the announcement of the new rules. Combined with previous results, this suggests that adjustment costs are positive but low, and that FYAs are effective in stimulating investment within a reasonably short time frame.

\subsection{Alternative definition of the treated group}

In the above analysis, we only use turnover to classify the treated and control groups. Using this approach, we may include firms that should not be in the treatment group-if these firms had high levels of employment and total assets. As a result, our benchmark estimates may be biased downward. Next, we consider an alternative definition of 
the treatment group. To allocate firms to the new treatment group, we employ two thresholds jointly: the one on total assets and the one on turnover. More specifically, to be assigned to the new treatment group, we require companies to report turnover above $\$ 11.2$ million and total assets above $\$ 5.6$ million in each year before the reform. For years after the reform, treated firms are required to report turnover below $\$ 22.8$ million and total assets below $\$ 11.4$ million. The control group is also constructed using both turnover and total assets thresholds. This is a stricter requirement than that used in our benchmark analysis, which implies less measurement error in our classification. The result of using a stricter classification is that we are left with a much smaller number of treated firms (237 in the treatment group versus 906 in the benchmark specification). As employment is largely unobserved, this stricter classification may also falsely exclude firms that should be in the treatment group. For example, a capitalintensive firm with turnover and employees below the thresholds after the reform should be in the treatment group. As the firm is capital intensive, its total assets might exceed the SME threshold. As we only use turnover and total assets for classification, this firm will not be in our second treatment group.

By comparing our benchmark treatment group and this new treatment group (Appendix D), we do not find these two groups are significantly different in terms of the growth rate of turnover or total assets, the level of turnover, investment rate, profitability, the marginal tax rate, or the cash flow before the policy reform. Unsurprisingly, we find that firms in the benchmark treatment group and excluded from the second treatment group tend to be larger in terms of total assets. Interestingly, we do not find any significant difference between the two groups of firms in terms of turnover or profitability. This supports our hypothesis that the excluded firms are likely to be capital intensive.

Table 9 reports the estimation results under the new, stricter classification. We control for common business cycle effects in columns (1) and (3), and sector-specific business cycle effects in columns (2) and (4). The estimated coefficient on $d_{i, t}^{R} \times d_{i}^{T}$ is 0.044 when we do not include firm-level characteristics (columns (1) and (2)). The point estimate increases to 0.049 when we include firm-level control variables (columns (3) and (4)). These point estimates are larger than the corresponding benchmark estimates in Table 6 . Nonetheless, the $Z$ test suggests that these point estimates are not statistically different. For example, when comparing the point estimate in column (6) of Table 6 to that in column (4) of Table 9 , we obtain $Z=-1.301 .^{17}$

When we use both thresholds to classify the treatment, we may fail to include capital-intensive firms in the treatment group as discussed above. It is unclear whether capital-intensive firms would have a higher or a lower tendency to invest. Therefore,

${ }^{17}$ The $\mathrm{Z}$ test statistics $=\frac{\beta_{3}-\beta_{3}^{\prime}}{\sqrt{\left(S E \beta_{3}\right)^{2}+\left(S E \beta_{3}^{\prime}\right)^{2}}}$, where $\beta_{3}$ and $\beta_{3}^{\prime}$ correspond to the estimated treatment effect using the benchmark and the alternative classifications, seperately. $S E \beta_{3}$ and $S E \beta_{3}^{\prime}$ are associated standard errors. 
estimates based on the two thresholds may still be biased due to selection, but the direction of such bias is unclear. Although we are unable to address these issues due to lack of information on employment, we believe that our benchmark estimates are likely to be biased downward and thus, they should serve as the lower bound for the treatment effect.

\subsection{Placebo tests}

We carry out three placebo tests. In the first test, we use firms that were always medium-sized as the treated group. We continue to use the never-qualified firms as the control group. For both groups, the rate of FYAs did not change: for mediumsized firms the rate was 40 per cent throughout our sample period and for large firms which could not claim FYAs, the rate remained at 25 per cent. Column (1) of Table 10 shows that the estimated coefficient $\beta_{3}$ is not statistically different from 0 .

In the second placebo test, we create an alternative treatment group from the set of firms that never qualified for FYAs, which are in our benchmark control group. The definition of the new treatment group is somewhat arbitrary here. We allocate firms into the new treatment group if their turnover is above $\$ 11.2$ million in each year before the reform and between $\$ 45.6$ and $\$ 91.2$ million in each year after the reform. Companies in the new treatment group have always enjoyed WDAs at $25 \%$ and hence, their investment behavior should not be different from that of the control group. Our finding is consistent with this hypothesis. In column (2), the estimated coefficient $\beta_{3}$ is again not statistically different from zero.

In the final placebo test, we consider changes in non-qualified investment following the reform. We do not directly observe the amount of non-qualified capital expenditures from our data sources. Therefore, we infer the amount of non-qualified capital expenditures as the difference between total investment and qualified investment. Total investment is calculated as the change in fixed assets from the previous year. In column (3), we report the estimation result. The point estimate is essentially 0 , which suggests that the availability of FYAs had no impact on non-qualified investment.

We conduct three different placebo tests in this section and we do not find treatment effect in any of the placebo tests. This lends further support to our benchmark findings.

\subsection{Other robustness checks}

To further check the reliability of our benchmark results, we conduct a number of robustness checks. To be succinct, we briefly discuss the findings here and provide more details in Appendix E.

One concern is whether the control group is truly comparable to the treated group. By construction, firms in the control group are larger than firms in the treatment group, and hence could be subject to different investment trends. In Table E1, we drop the 
top $5 \%$ (column (1)) or the top $50 \%$ (column (2)) of companies in the control group in terms of total assets. The estimated coefficient $\beta_{3}$ on the interactive term $d_{i, t}^{R} \times d_{i}^{T}$ remains positive and statistically significant in both columns, with a magnitude of between 0.023 and 0.024 , close to our benchmark result. We also exclude large firms from the control group based on the distribution of turnover. The results are virtually identical and hence, are not reported here for brevity.

As a further check, we match companies in the control group to companies in the treatment group by constructing a propensity score (for being treated) based on observed firm characteristics. Column (3) of Table E1 reports the weighted regression results for the matched sample. The estimated coefficient $\beta_{3}$ on the interaction term is positive, statistically significant and very close in magnitude to those estimates in our benchmark specifications.

Another possible confounding factor is the anticipation effect. For example, if firms anticipated the UK reform shortly before its announcement on 10 December 2003, firms whose financial year ended in December 2003 could have delayed qualifying expenditure to 2004 in order to receive the benefit of FYAs. ${ }^{18}$ If this type of anticipatory effect is driving the estimated tax effect on investment, we should observe a drop in the investment rate of firms with a December year-end one year before the reform (labelled as Year 0) and a larger increase in Year 1, relative to other treated firms. Figure 2 plots the average gross investment rate of treated firms with a December year-end, and that of other treated firms. While there is indeed a drop in the investment rate of December year-end firms in Year 0 relative to other treated firms, the difference is tiny and statistically insignificant. The investment rate of December year-end firms is actually lower in Year 1 relative to other treated firms. As discussed in Section 4.2, it is also unlikely that firms anticipated the UK reform well in advance, for example, after the European Commission's May announcement. Taking all these results together, we do not find that anticipation affects our benchmark results.

\section{Bunching at qualifying thresholds}

The presence of FYAs available only for companies below a certain size threshold creates notches in the cost of capital. ${ }^{19}$ To qualify for FYAs, companies may manipulate their size indicators. In particular, firms with a high propensity to invest regardless of FYAs could manipulate their size indicators to qualify for FYAs - and the incentive for such manipulation increases with planned investment. If this is the case, our benchmark estimates may be biased. We analyze this concern in this section.

If companies manipulate their size indicators to qualify for FYAs, we should observe an abnormal mass to the left of the threshold in the distribution of turnover or

\footnotetext{
${ }^{18}$ Firms with a year end in December account for around two thirds of our sample.

${ }^{19}$ For definition of a tax notch, see Slemrod (2013).
} 
total assets, and a missing mass to the right. The top panel of Figure 3A provides some evidence that companies bunched just to the left of the old threshold (£11.2m) before the reform. However, the distribution of turnover around the old threshold became smooth after the reform (bottom panel of Figure 3A). Interestingly, companies appear to bunch below the new threshold $(£ 22.8 \mathrm{~m})$ after the reform (bottom panel of Figure 3B), although not before the reform (upper panel of Figure 3B). In unreported exercises, we find somewhat similar patterns in the distribution of total assets, but bunching behaviour around the discontinuity in the distribution of total assets is not as significant as around the discontinuity in the distribution of turnover. Unfortunately, we cannot analyze the distribution of the number of employees as the variable is largely missing. In addition to these graphical evidence, we formally test whether there is excess mass to the left of the relevant threshold in the distribution of turnover (or total assets). ${ }^{20}$ We obtain positive bunching estimates around relevant thresholds, which is consistent with the figures. Nonetheless, these bunching estimates are not statistically significant.

If firms self-selected into treatment and they also had a higher propensity to invest regardless of the tax incentives, our estimated treatment effect would be biased upward. The statistically insignificant bunching estimates suggest that self-selection may not be a crucial concern. Nevertheless, as a robustness check, we exclude firms that are close to the new qualifying threshold for turnover. This excludes firms whose turnover was between $£ 22$ million and $£ 22.8$ million at least once after the reform. Effectively, we drop 49 firms from the treated group ( $5.4 \%$ of the treated). The estimation results are reported in Table 11. In column (1), we include a common set of year dummies. In column (2), we include sector-year dummies.

In Table 11, the estimated coefficient on the interaction between the treatment and post-reform dummies remains positive and highly significant, and its magnitude is virtually the same as that in the benchmark estimations. In unreported estimations, we obtain similar results if we also drop companies clustering around the new threshold for total assets. For brevity, we do not report these results here. Taken together, these estimates imply that FYAs were effective in stimulating investment for a wider group of companies other than only affecting the behavior of firms that were able to manage their size indicators.

\section{Is the cash flow effect important?}

Capital allowances may affect investment via two main channels - by lowering the cost of capital, and for cash constrained firms, by increasing the availability of cash due to reduced tax liabilities. In this section, we exploit variation in the timing of corporation

\footnotetext{
${ }^{20}$ We calculate the bunching statistics as in Chetty et al. (2011) using the code provided by Professor Raj Chetty, which is available on http://www.rajchetty.com/utilities/.
} 
tax payments to test the relative importance of these two channels.

In the UK, larger firms with taxable income above $£ 1.5$ million in the current and preceding financial years must pay the corporation tax liability by quarterly installments within their financial year. However, the majority of smaller UK companies can settle their corporation tax liability nine months after their accounting year end. Cash savings due to a reduced tax liability would only arise when actual taxes are paid and therefore, if the cash flow effect dominates the user cost effect, we expect to see a change in investment in Year 2 rather than Year 1 for treated firms paying their corporation taxes in arrears. We test this hypothesis in Table 12. In column (1) a company is defined as paying in arrears if its taxable income in Year 0 and Year 1 is below $£ 1.5$ million. As a robustness check, in column (2), companies are defined as paying in arrears if their taxable income is below $£ 1.5$ million in every year in our sample period. ${ }^{21}$

In columns (1) and (2) of Table 12, we focus on firms with accounts ending in the second half of the calendar year (from July to December) and settling their tax liabilities in arrears. These firms had sufficient time to adjust investment in Year 1 and would do so if they were not financially constrained. In contrast, if these firms were financially constrained, they would more likely have to adjust investment in Year 2 when their after-tax income increased. We observe that these firms reacted strongly to the reform in Year 1-the estimated coefficient on the interaction between the treatment dummy and the dummy for Year 1 is positive and statistically significant. The point estimate is also large in magnitude. These results indicate that firms increased investment in Year 1 when FYAs reduced the user cost of capital, even though no actual tax savings had been realized by then. Thus, the increase in investment is mainly driven by the cost of capital effect.

As a further check, we use more conventional cash flow measures to identify firms that are likely to be financially constrained, although Farre-Mensa and Ljungqvist (2015) caution that standard measures of financial constraints (such as credit rating, dividends, cash flow, firm age, size, and leverage) may not identify accurately firms' financial status. More specifically, we adopt a triple-difference approach where we interact the indicator of firms' financial status with variables in Equation (1). We assume companies are more likely to be financially constrained (a) if they had negative lagged cash flow, or (b) if they had a lagged cash flow below the sample mean. ${ }^{22}$ Cash flow is defined as the sum of profits before tax plus depreciation, scaled by total assets. Among the treated, $17 \%$ of observations had negative cash flow and $52 \%$ of them had cash flow below the mean. In the control group, $12 \%$ of observations reported negative lagged cash flow and $51 \%$ of them had lagged cash flow below the mean. In columns (3), we find that treated firms with negative cash flow did not react differently from

\footnotetext{
${ }^{21}$ Overall, 2,285 firms in our benchmark sample always pay in arrears (66 per cent) and 1,188 firms always pay in instalment.

${ }^{22}$ Using the median of cash flow to split the sample does not affect the results.
} 
other treated firms. In column (4), we do not find that treated firms with cash flow above the sample mean responded differently to FYAs. Other studies also use firm size as an indicator of firms' financial status-smaller firms are more likely to be financially constrained. This does not seem to be true in our dataset as the relationship between size and cash flow (scaled by total assets) is non-monotonic (Figure F1, Appendix F). For this reason, we do not employ size as a measure of financial constraints.

As another approach, we identify firms in our sample that belong to a corporate group. Such firms are less likely to be financially constrained if there is an efficient internal capital market and hence, they should react less to the tax incentive than stand-alone firms which are more likely to be financially constrained. Using the ownership information available in FAME, we define companies as part of a group if they directly or indirectly own more than $50 \%$ of some subsidiaries or if they are owned directly or indirectly by another corporation. By this definition, among the treated, 753 firms (83\%) are part of a group and 153 are stand-alone; for the control group, 2,367 (92\%) are part of a group and 200 are stand-alone. In column (5) of Table 12 we implement a triple difference approach with a dummy for standalone companies interacted with the benchmark specification. The estimated coefficient $\beta_{3}$ remains positive, significant and close in magnitude to our benchmark estimates. The coefficient on the triple interaction $\left(d_{i, t}^{R} \times d_{i}^{T} \times S\right.$ tand-alone company $)$ is negative but statistically insignificant. Thus, there is no evidence that stand-alone firms, which are more likely to be financially constrained, responded more to FYAs.

Taking these results together, we do not find evidence that the cash flow effect is a key channel through which FYAs stimulate investment of our treated firms. This result seems to be at odds with some previous studies (for example, Zwick and Mahon, 2017) who find the cash-flow effect associated with bonus depreciation to be important. However, our results could arise if firms in our sample were not financially constrained. Throughout our sample period (2002/03-2006/07), the UK economy was expanding at an average GDP growth rate of $3 \%$ per annum and hence, was in a boom period. ${ }^{23}$ In this period, credit was also easily available. Lending to UK businesses expanded rapidly between December 2003 (when higher thresholds were announced) and December 2006, often growing at double digits yearly rates (Bank of England, 2009, 2010). By contrast, bonus depreciation in the US was implemented during two economic downturns. The different economic environment could explain the difference between our result and previous findings. Overall, our analysis shows that the cost of capital effect is of first-order importance. Therefore, accelerated depreciation allowances could be used by policy makers to effectively boost SMEs' investment even during non-recession periods and more generally, when firms are less likely to be financially constrained.

\footnotetext{
${ }^{23}$ Long-term profile of Gross Domestic Product (GDP) in the UK, ONS (2013).
} 


\section{Conclusions}

Using confidential UK corporation tax return data, we analyze the effects of tax incentives in the form of accelerated first-year capital allowances on companies' investment spending. We exploit an exogenous change in the user cost of capital for small UK private companies due to an exogenous variation in the qualifying thresholds for higher first-year capital allowances. We find that access to more generous capital allowances increases firms' investment by between 2.1 and 2.5 percentage points. In contrast to much of the rest of the literature, we do not find evidence of a cash flow effect and hence, this increase in investment was mainly due to the reduction in the user cost of capital following the reform. Our findings are robust to a number of tests.

Our findings suggest that governments can effectively stimulate investment by providing more generous capital allowances for capital expenditures as an alternative to lowering the statutory corporate income tax rate. Additionally, the reaction of firms to increased capital allowances is rather quick (within a maximum of between 12 to 18 months), pointing to the fact that tax policy delivered through capital allowances can be rapidly effective in stimulating investment in plant and machinery. Overall, our results widen the policy makers' tool box beyond the standard policy advice to reduce the statutory corporate income tax rate. One interesting issue that we have not explored yet is how accelerated capital allowances targeting plant and machinery affect the composition of capital assets over time, especially when the tax incentives are perceived to be permanent. We leave this question for future research. 


\section{References}

[1] Auerbach, A. J., and Hassett, K.J., "Tax policy and business fixed investment in the United States." Journal of Public Economics, 47(2): 141-170, 1992.

[2] Bank of England, "Trends in Lending", 2009, 2010.

[3] Bertrand, M., Duflo, E., and Mullainathan, S., "How much should we trust differences-in-differences estimates?", The Quarterly Journal of Economics, 119(1): 249-275, 2004.

[4] Bond, S., and Xing, J., "Corporate taxation and capital accumulation: Evidence from sectoral panel data for 14 OECD countries", Journal of Public Economics, 130: 15-31, 2015.

[5] Department for Business, Energy \& Industrial Strategy, "Business Population Estimate for the UK and Regions", 2017. Available at https://www.gov.uk/government/statistics/business-population-estimates-2017.

[6] Chetty, R., Friedman, J. N., Olsen, T., and Pistaferri, L., "Adjustment costs, firm responses, and micro vs. macro labor supply elasticities: evidence from Danish tax records", The Quarterly Journal of Economics, 126(2): 749-804, 2011.

[7] Chetty, R., Looney, A., and Kroft, K., "Salience and taxation: theory and evidence", American Economic Review, 99(4): 1145-1177, 2009.

[8] Chirinko, R.S., Fazzari, S.M., and Meyer, A.P., "How responsive is business capital formation to its user cost? An exploration with micro data", Journal of Public Economics, 74(1): 53-80, 1999.

[9] Cummins, J.G., Hassett, K.A., Hubbard, G.R., "A reconsideration of investment behavior using tax reforms as natural experiments", Brookings Papers on Economic Activity, 2: 1-74, 1994.

[10] Desai, M. A., and Goolsbee, A.D., "Investment, overhang, and tax policy.", Brookings Papers on Economic Activity, 35(2): 285-355, 2004.

[11] Edgerton, J., "Investment incentives and corporate tax asymmetries.", Journal of Public Economics, 94(11-12): 936-952, 2010.

[12] Farre-Mensa, J., and Ljungqvist, A., "Do Measures of Financial Constraints Measure Financial Constraints?", Review of Financial Studies, forthcoming.

[13] Feldstein M., "Europe has to face the threat of America's trade deficit", The Financial Times, 2 August, 2006.

[14] Freedman, J., "Small Business Taxation: Policy Issues and the UK" in N. Warren (ed), Taxing Small Business: Developing Good Tax Policies, Australian Tax Research Foundation, 2003.

[15] Hadlock, C. J., and Pierce, J. R. "New Evidence on Measuring Financial Constraints: Moving Beyond the KZ Index", The Review of Financial Studies, 23 (5): 1909-1940, 2010. 
[16] Hall, R.E., and Jorgenson, D. W., "Tax Policy and Investment Behavior." American Economic Review, 57(3): 391-414, 1967.

[17] Hayashi, F., "Tobin's Marginal q and Average q: A Neoclassical Interpretation." Econometrica, 50(1): 213-224, 1982.

[18] House, C., and Shapiro, M., "Temporary Investment Tax Incentives: Theory with Evidence from Bonus Depreciation." American Economic Review, 98(3): 737-68, 2008.

[19] Guceri, I., and Liu, L., "Effectiveness of fiscal incentives for R\&D: quasiexperimental evidence", American economic Journal: economic Policy, forthcoming.

[20] Jorgenson, Dale W., "Capital theory and investment behavior", The American Economic Review 53(2), 247-259, 1963.

[21] Maffini, G., "Corporate Tax Policy under the Labour Government: 1997-2010", Oxford Review of Economic Policy, 29 (1): 142-164, 2013.

[22] Ohrn, E., "The Effect of Corporate Taxation on Investment and Financial Policy: Evidence from the DPAD", The American Economic Journal: Economic Policy, 10 (2): 272-301, 2018a.

[23] Ohrn, E., "The Effect of Tax Incentives on U.S. Manufacturing: Evidence from State Accelerated Depreciation Policies “, memo, 2018b.

[24] ONS, "Long-term profile of Gross Domestic Product (GDP) in the UK", 2013. Available at: http://www.ons.gov.uk/ons/rel/elmr/explaining-economicstatistics/long-term-profile-of-gdp-in-the-uk/sty-long-term-profile-of-gdp.html.

[25] Tiley J., and Loutzenhiser, G., "Capital Allowances (Chapter 6)", in Advanced Topics in Revenue Law, Hart Publishing, Oxford and Portland, Oregon, 2013.

[26] Standing Committee on Bills, "Finance Bill 2004 - Clause 132 - Temporary increase in amount of first-year allowances for small enterprises", 25 May 2004. Available at http://www.publications.parliament.uk/pa/cm200304/cmstand/a/st040525/pm/40525s11.htm

[27] Slemrod, Joel, "Buenas noches: Lines and notches in tax system design." Mimeo, University of Michigan, 2010.

[28] Summers, L. H., "Taxation and Corporate Investment: A q-Theory Approach." Brookings Papers on Economic Activity, 1981(1): 67-140, 1981.

[29] Zwick, Eric, and James Mahon, "Tax Policy and Heterogeneous Investment Behavior," American Economic Review, 107(1): 217-48, 2017. 

$(\%)$

Table 1: Rates of capital allowances for plant and machinery in first year

\begin{tabular}{ccccc}
\hline \hline & Treated & Control & Always small & Always medium \\
\hline $2001 / 02$ & 25 & 25 & 40 & 40 \\
$2002 / 03$ & 25 & 25 & 40 & 40 \\
$2003 / 04$ & 25 & 25 & 40 & 40 \\
$2004 / 05$ & 40 & 25 & 50 & 40 \\
$2005 / 06$ & 40 & 25 & 40 & 40 \\
$2006 / 07$ & 40 & 25 & 50 & 40 \\
$2007 / 08$ & 40 & 25 & 50 & 40 \\
$2008 / 09$ & 20 & 20 & 20 & 20 \\
\hline
\end{tabular}

Notes: Treated firms were large before the 2004/05 change in the definition of SMEs, so they could not qualify for FYAs. They became qualified for FYAs subsequently. Large firms never qualified for FYAs.

Table 2: Conditions for qualifying as SME for FYAs purposes

\begin{tabular}{lcc}
\hline \hline Category & Small-sized & Medium-sized \\
\hline \multicolumn{3}{c}{ Before the reform } \\
Turnover & $\leq £ 2.8 \mathrm{~m}$ & $\leq £ 11.2 \mathrm{~m}$ \\
Assets & $\leq £ 1.4 \mathrm{~m}$ & $\leq £ 5.6 \mathrm{~m}$ \\
Employees & 50 & 250 \\
\hline \multicolumn{3}{c}{ After the reform } \\
Turnover & $\leq £ 5.6 \mathrm{~m}$ & $\leq £ 22.8 \mathrm{~m}$ \\
Assets & $\leq £ 2.8 \mathrm{~m}$ & $\leq £ 11.4 \mathrm{~m}$ \\
Employees & 50 & 250 \\
\hline
\end{tabular}

Notes: The before-reform period includes financial years ending before 30 January 2004. The after-reform period includes financial years ending on or after 30 January 2004.

Table 3: Corporate income tax rates (\%)

\begin{tabular}{lcccccccc}
\hline \hline Taxable income $(£)$ & $2001 / 02$ & $2002 / 03$ & $2003 / 04$ & $2004 / 05$ & $2005 / 06$ & $2006 / 07$ & $2007 / 08$ & $2008 / 09$ \\
\hline $0-10,000$ & 10 & 0 & 0 & 0 & 0 & 19 & 20 & 21 \\
$10,001-50,000$ & 22.5 & 23.75 & 23.75 & 23.75 & 23.75 & 19 & 20 & 21 \\
$50,001-300,000$ & 20 & 19 & 19 & 19 & 19 & 19 & 20 & 21 \\
$300,001-1,500,000$ & 32.5 & 32.75 & 32.75 & 32.75 & 32.75 & 32.75 & 32.5 & 29.75 \\
$>1,500,000$ & 30 & 30 & 30 & 30 & 30 & 30 & 30 & 28 \\
\hline
\end{tabular}

Notes: This table reports the corporate income marginal tax rate schedule in the UK between fiscal years 2001/02 and 2008/09. For taxable income between $£ 300,000$ and $£ 1.5$ million, the corporation tax is calculated at the main rate minus the marginal relief. The marginal relief is calculated as follows. Marginal relief $=(£ 1.5 \mathrm{~m}-$ Profits $) \times$ Standard Fraction. This implies that an effective marginal rate of between 19 and 32.5 per cent has been applying on profits in excess of $£ 300,000$ and below $£ 1,500,000$. The standard fraction was $1 / 40$ in 2001/02 and 2007/08, 11/40 between $2002 / 03$ and $2006 / 07$ and $7 / 440$ in 2008/09. When the starting rate was available, the marginal relief applicable on profits between $£ 10,000$ and $£ 50,000$ was $1 / 40$ in $2001 / 02$ and $11 / 40$ between 2002/03 and 2006/07. 
Table 4: Descriptive statistics of key variables

\begin{tabular}{lcccccc}
\hline \hline & \multicolumn{3}{c}{ Treated } & \multicolumn{3}{c}{ Control } \\
\hline Variables & Mean & S.D. & Obs. & Mean & S.D. & Obs. \\
\hline Turnover (GBP, in thousands) & 15,700 & 4,865 & 4,530 & 169,000 & 828,000 & 12,835 \\
Growth rate of turnover & -0.0242 & 0.170 & 4,530 & 0.0706 & 0.180 & 12,835 \\
Total assets (GBP, in thousands) & 26,100 & 120,000 & 4,530 & 219,000 & $4,020,000$ & 12,835 \\
Growth rate of total assets & -0.073 & 0.632 & 4,530 & 0.021 & 0.721 & 12,835 \\
Profitability & 0.044 & 0.080 & 4,530 & 0.052 & 0.090 & 12,835 \\
Marginal tax rate & 0.143 & 0.150 & 4,530 & 0.170 & 0.150 & 12,835 \\
Gross investment rate & 0.183 & 0.33 & 4,530 & 0.205 & 0.34 & 12,835 \\
Cash flow & 0.063 & 0.305 & 4,407 & 0.082 & 0.306 & 12,527 \\
\hline
\end{tabular}

Note: In this table, we report the means and standard deviations of key variables in our estimations. We report these statistics for the treatment and the control groups seperately. Variables are defined in Table B2 in Appendix B.

Table 5: Gross investment rate

\begin{tabular}{|c|c|c|c|c|c|c|}
\hline \multicolumn{7}{|l|}{ Treatment group } \\
\hline \multirow[b]{3}{*}{ Investment rate } & \multicolumn{2}{|c|}{ Non-qualifying years } & \multicolumn{2}{|c|}{ Qualifying years } & \multirow{3}{*}{$\begin{array}{c}\text { t-test statistics } \\
-2.258\end{array}$} & \multirow{3}{*}{$\begin{array}{c}\operatorname{Pro}(\mathrm{T}<\mathrm{t}) \\
0.012\end{array}$} \\
\hline & Mean & S.D. & Mean & S.D. & & \\
\hline & 0.169 & 0.300 & 0.192 & 0.349 & & \\
\hline Obs. & 1,812 & & 2,718 & & & \\
\hline \multicolumn{7}{|l|}{ Control group } \\
\hline & \multicolumn{2}{|c|}{ Before policy change } & \multicolumn{2}{|c|}{ After policy change } & & \\
\hline & Mean & S.D. & Mean & S.D. & t-test statistics & $\operatorname{Pro}(\mathrm{T}<\mathrm{t})$ \\
\hline Investment rate & 0.203 & 0.337 & 0.205 & 0.337 & -0.356 & 0.360 \\
\hline Obs. & 5,134 & & 7,701 & & & \\
\hline
\end{tabular}

Notes: We report the gross investment rate of the treatment and the control groups before and after the policy change. We also report the results from the t-test of the null hypothesis that the mean investment rate during non-qualifying years (before policy change) equals to that during qualifying years (after policy change). 
Table 6: Estimated response of investment rate to tax subsidy: baseline estimates

\begin{tabular}{lcccccc}
\hline \hline Dependent var: $I_{i, t} / K_{i, t-1}$ & $(1)$ & $(2)$ & $(3)$ & $(4)$ & $(5)$ & $(6)$ \\
\hline$d_{i, t}^{R} \times d_{i}^{T}$ & 0.021 & 0.022 & 0.022 & 0.023 & 0.025 & 0.025 \\
& $(0.012)$ & $(0.012)$ & $(0.012)$ & $(0.010)$ & $(0.012)$ & $(0.012)$ \\
$d_{i, t}^{R}$ & 0.002 & 0.001 & & & & \\
& $(0.007)$ & $(0.007)$ & & & & \\
Growth rate of turnover ${ }_{i, t}$ & & 0.111 & 0.112 & 0.109 & 0.116 & 0.114 \\
& & $(0.016)$ & $(0.016)$ & $(0.016)$ & $(0.016)$ & $(0.016)$ \\
$M T R_{i, t}$ & & & & & -0.042 & -0.042 \\
& & & & & $(0.021)$ & $(0.022)$ \\
Profitability $i_{i, t-1}$ & & & & & 0.298 & 0.300 \\
& & & & & $(0.047)$ & $(0.048)$ \\
Growth rate of total assets $s_{i, t}$ & & & & & 0.015 & 0.015 \\
& & & & & $(0.006)$ & $(0.006)$ \\
Year FE & No & No & Yes & No & Yes & No \\
Sector-year FE & No & No & No & Yes & No & Yes \\
Firm FE & Yes & Yes & Yes & Yes & Yes & Yes \\
No. of firms & 3,473 & 3,473 & 3,473 & 3,473 & 3,473 & 3,473 \\
No. of obs. & 17,365 & 17,365 & 17,365 & 17,365 & 17,365 & 17,365 \\
\hline
\end{tabular}

Notes: In this table, we report the benchmark estimation results based on Equation (1). The dependent variable is capital expenditures in qualified assets of firm $i$ in year $\mathrm{t}\left(I_{i, t}\right)$, scaled by fixed assets in year $t-1\left(K_{i, t-1}\right) ; d_{i, t}^{R}$ is a dummy equal to one for financial year ending on or after 30 January 2004, when the new thresholds for qualifying for FYAs applied. $d_{i}^{T}$ is a dummy equal to one for the treatment group. Except in column 1, we control for a set of firm-level characteristics including the growth rate of turnover in year $t$; the marginal corporate income tax rate in year $t\left(M T R_{i, t}\right)$; the lagged profitability and the growth rate of total assets in year $t$. The estimated coefficient on $d_{i, t}^{R} \times d_{i}^{T}$ captures the effect of the first-year capital allowances on investment rate in qualified assets. There are 906 firms in the treatment group (4,530 observations) and 2,567 firms in the control group $(12,835$ observations). Heteroscedasticity and cluster-robust standard errors are in parentheses. The unit of clustering is the industry of the firm. 
Table 7: Estimated response of $\ln (C A P X)$ to tax subsidy

\begin{tabular}{lcc}
\hline \hline Dependent var: & & \\
$\ln (C A P X)_{i, t}$ & $(1)$ & $(2)$ \\
\hline $\mathrm{d}_{i, t}^{R} \times d_{i}^{T}$ & 0.161 & 0.169 \\
& $(0.094)$ & $(0.097)$ \\
Control variables & Yes & Yes \\
Year FE & Yes & \\
Sector-year FE & & Yes \\
Firm FE & Yes & Yes \\
No. of firms & 3,473 & 3,473 \\
No. of obs. & 16,150 & 16,150 \\
\hline
\end{tabular}

Notes: This table reports the estimated treatment effect when the dependent variable is the level of qualified investment (in logs). We control for firm-level characteristics including the level of turnover (in logs), size, the lagged profitability and firm-specific marginal tax rate. Heteroscedasticity and cluster-robust standard errors are in parentheses. The unit of clustering is the industry of the firm. 
Table 8: Estimated response of investment rate to tax subsidy: adjustment costs

\begin{tabular}{lcccc}
\hline \hline \multirow{2}{*}{ Dependent var: $I_{i, t} / K_{i, t-1}$} & $(1)$ & $(2)$ & \multicolumn{2}{c}{ Not balanced after reform } \\
& Jan-June & July-Dec & Jan-June & July-Dec \\
\hline$d_{i}^{T} \times$ Year 1 & 0.000 & 0.036 & 0.005 & 0.020 \\
& $(0.032)$ & $(0.015)$ & $(0.028)$ & $(0.010)$ \\
$d_{i}^{T} \times$ Year 2 & 0.053 & 0.012 & 0.076 & -0.005 \\
& $(0.034)$ & $(0.019)$ & $(0.031)$ & $(0.019)$ \\
$d_{i}^{T} \times$ Year 3 & 0.086 & 0.024 & 0.076 & 0.026 \\
& $(0.030)$ & $(0.015)$ & $(0.027)$ & $(0.010)$ \\
Control variables & Yes & Yes & Yes & Yes \\
Sector-year FE & Yes & Yes & Yes & Yes \\
Firm FE & Yes & Yes & Yes & Yes \\
No. of firms & 427 & 3,046 & 500 & 3,712 \\
No. of obs. & 2,135 & 15,230 & 2,448 & 17,811 \\
\hline
\end{tabular}

Notes: In columns (1) and (3), the sample contains only companies with year-end between January and June. In columns (2) and (4), the sample contains only companies with year-end between July and December. We control for the growth rate of turnover, lagged profitability, the marginal tax rate, and the growth rate of total assets throughout different columns. Heteroscedasticity and cluster-robust standard errors are in parentheses. The unit of clustering is the industry of the firm.

Table 9: Estimated response of investment rate to tax subsidy: use both turnover and total assets thresholds to classify the treated group

\begin{tabular}{lcccc}
\hline \hline Dependent variable: & $(1)$ & $(2)$ & $(3)$ & $(4)$ \\
\hline & & & & \\
$d_{i, t}^{R} \times d_{i}^{T}$ & 0.044 & 0.044 & 0.049 & 0.049 \\
& $(0.014)$ & $(0.014)$ & $(0.014)$ & $(0.014)$ \\
Growth rate of turnover ${ }_{i, t}$ & & & 0.109 & 0.011 \\
& & & $(0.018)$ & $(0.018)$ \\
$M T R_{i, t}$ & & & -0.036 & -0.040 \\
& & & $(0.023)$ & $(0.022)$ \\
Profitability $_{i, t-1}$ & & & 0.218 & 0.215 \\
& & & $(0.050)$ & $(0.050)$ \\
Growth rate of total assets $i, t$ & & & 0.017 & 0.016 \\
& & & $(0.008)$ & $(0.008)$ \\
Year FE & Yes & No & Yes & No \\
Sector-year FE & No & Yes & No & Yes \\
Firm FE & Yes & Yes & Yes & Yes \\
No. of firms & 2,559 & 2,559 & 2,559 & 2,559 \\
No. of obs. & 12,795 & 12,795 & 12,795 & 12,795 \\
\hline
\end{tabular}

Notes: In this table, we report the estimation results based on Equation (1). We construct the treatment and the control groups using both total assets and turnover thresholds. Heteroscedasticity and cluster-robust standard errors are in parentheses. The unit of clustering is the industry of the firm. 
Table 10: Placebo tests

\begin{tabular}{lccc}
\hline \hline & $(1)$ & $(2)$ & $(3)$ \\
Dependent variable: & $I_{i, t} / K_{i, t-1}$ & $I_{i, t} / K_{i, t-1}$ & $I_{i, t}^{\text {Non-qualified }} / K_{i, t-1}$ \\
\hline \multirow{2}{*}{$d_{i, t}^{R} \times d_{i}^{T}$} & & & \\
& 0.006 & -0.018 & 0.006 \\
Control variables & $(0.011)$ & $(0.016)$ & $(0.007)$ \\
Sector-year FE & Yes & Yes & Yes \\
Firm FE & Yes & Yes & Yes \\
No. of firms & Yes & Yes & Yes \\
No. of obs. & 3,897 & 2,516 & 3,451 \\
& 19,845 & 12,580 & 16,132 \\
\hline
\end{tabular}

Notes: We present results from three placebo tests in this table. In Column 1, we use firms that were always medium-sized as the treatment group. In Column 2, we create an alternative treatment group from the set of larger firms that never qualified for FYAs. In Column 3, we use the original classification for the treatment and control groups but use non-qualified investment rate as the dependent variable. We control for the growth rate of turnover, lagged profitability, the marginal tax rate, and the growth rate of total assets throughout different columns. Heteroscedasticity and cluster-robust standard errors are in parentheses. The unit of clustering is the industry of the firm.

Table 11: Estimated response of investment rate to tax subsidy: excluding companies bunching at turnover thresholds

\begin{tabular}{lcc}
\hline \hline Dependent variable: & & \\
$I_{i, t} / K_{i, t-1}$ & $(1)$ & $(2)$ \\
\hline$d_{i, t}^{R} \times d_{i}^{T}$ & 0.024 & 0.025 \\
& $(0.012)$ & $(0.012)$ \\
\hline Control variables & Yes & Yes \\
Year FE & Yes & No \\
Sector-year FE & No & Yes \\
Firm FE & Yes & Yes \\
No. of firms & 3,424 & 3,424 \\
No. of obs. & 17,120 & 17,120 \\
\hline
\end{tabular}

Notes: We report results based on Equation (1) while excluding firms that bunched at the turnover threshold. These are companies with turnover between $£ 22 \mathrm{~m}$ and $£ 22.8 \mathrm{~m}$ at least once in Year 1,2 , or 3. In Column 1, we control for a common set of year dummies. In Column 2, we control for sectoryear fixed effects. In both columns, we control for the growth rate of turnover, lagged profitability, the marginal tax rate, and the growth rate of total assets. Heteroscedasticity and cluster-robust standard errors are in parentheses. The unit of clustering is the industry of the firm. 
Table 12: Testing for the cash flow effects

\begin{tabular}{|c|c|c|c|c|c|}
\hline Dependent var: $I_{i, t} / K_{i, t-1}$ & $\begin{array}{c}(1) \\
\text { In arrears } \\
\text { in Year } 1 \\
\end{array}$ & $\begin{array}{c}(2) \\
\text { Alway in } \\
\text { arrears }\end{array}$ & $\begin{array}{c}(3) \\
\text { Negative } \\
\text { cash flow }\end{array}$ & $\begin{array}{c}\text { (4) } \\
\text { Cash flow } \\
\text { above mean }\end{array}$ & $\begin{array}{c}(5) \\
\text { Ownership } \\
\text { structure }\end{array}$ \\
\hline$d_{i}^{T} \times Y$ ear 1 & $\begin{array}{c}0.040 \\
(0.021)\end{array}$ & $\begin{array}{c}0.037 \\
(0.019)\end{array}$ & & & \\
\hline$d_{i}^{T} \times Y$ ear 2 & $\begin{array}{c}0.019 \\
(0.021)\end{array}$ & $\begin{array}{l}0.020 \\
(0.020)\end{array}$ & & & \\
\hline$d_{i}^{T} \times Y$ ear 3 & $\begin{array}{c}0.035 \\
(0.016)\end{array}$ & $\begin{array}{c}0.039 \\
(0.018)\end{array}$ & & & \\
\hline$d_{i, t}^{R} \times d_{i}^{T}$ & & & $\begin{array}{c}0.025 \\
(0.012)\end{array}$ & $\begin{array}{c}0.035 \\
(0.019)\end{array}$ & $\begin{array}{c}0.027 \\
(0.011)\end{array}$ \\
\hline$d_{i, t}^{R} \times d_{i}^{T} \times$ Negative lagged cash flow & & & $\begin{array}{c}0.012 \\
(0.030)\end{array}$ & & \\
\hline$d_{i, t}^{R} \times d_{i}^{T} \times$ Lagged cash flow above mean & & & & $\begin{array}{l}-0.014 \\
(0.020)\end{array}$ & \\
\hline$d_{i, t}^{R} \times d_{i}^{T} \times$ Stand-alone company & & & & & $\begin{array}{l}-0.026 \\
(0.030)\end{array}$ \\
\hline Negative lagged cash flow & & & $\begin{array}{l}-0.033 \\
(0.014)\end{array}$ & & \\
\hline Lagged cash flow above mean & & & & $\begin{array}{c}0.010 \\
(0.010)\end{array}$ & \\
\hline$d_{i}^{T} \times$ Negative lagged cash flow & & & $\begin{array}{c}0.000 \\
(0.035)\end{array}$ & & \\
\hline$d_{i}^{T} \times$ Lagged cash flow above mean & & & & $\begin{array}{l}-0.005 \\
(0.020)\end{array}$ & \\
\hline$d_{i, t}^{R} \times$ Negative lagged cash flow & & & $\begin{array}{c}0.025 \\
(0.011)\end{array}$ & & \\
\hline$d_{i, t}^{R} \times$ Lagged cash flow above mean & & & & $\begin{array}{c}0.033 \\
(0.014)\end{array}$ & \\
\hline$d_{i, t}^{R} \times$ Stand-alone company & & & & & $\begin{array}{c}0.028 \\
(0.020)\end{array}$ \\
\hline Control variables & Yes & Yes & Yes & Yes & Yes \\
\hline Sector-year FE & Yes & Yes & Yes & Yes & Yes \\
\hline Firm FE & Yes & Yes & Yes & Yes & Yes \\
\hline No. of firms & 2,429 & 2,020 & 3,449 & 3,449 & 3,473 \\
\hline No. of obs. & 12,145 & 10,100 & 16,971 & 16,971 & 17,365 \\
\hline
\end{tabular}

Notes: In columns (1) and (2), companies have year-end between July and December. In column (1) all companies paid tax in arrears in qualifying year 1 . In column (2), all companies always paid in arrears. In column (3), Negative lagged cash flow is a dummy that equals 1 if cash flow is negative, and 0 otherwise. In column (4), Lagged cash flow above mean is a dummy that equals 1 if cash flow is above the mean cash flow, and 0 otherwise. In column (5), Stand-alone company is a dummy that equals 1 if a company does not belong to a corporate group. Heteroscedasticity and cluster-robust standard errors are in parentheses. The unit of clustering is the industry of the firm. 
Figure 1: Differences in investment rate between the treatment and the control groups

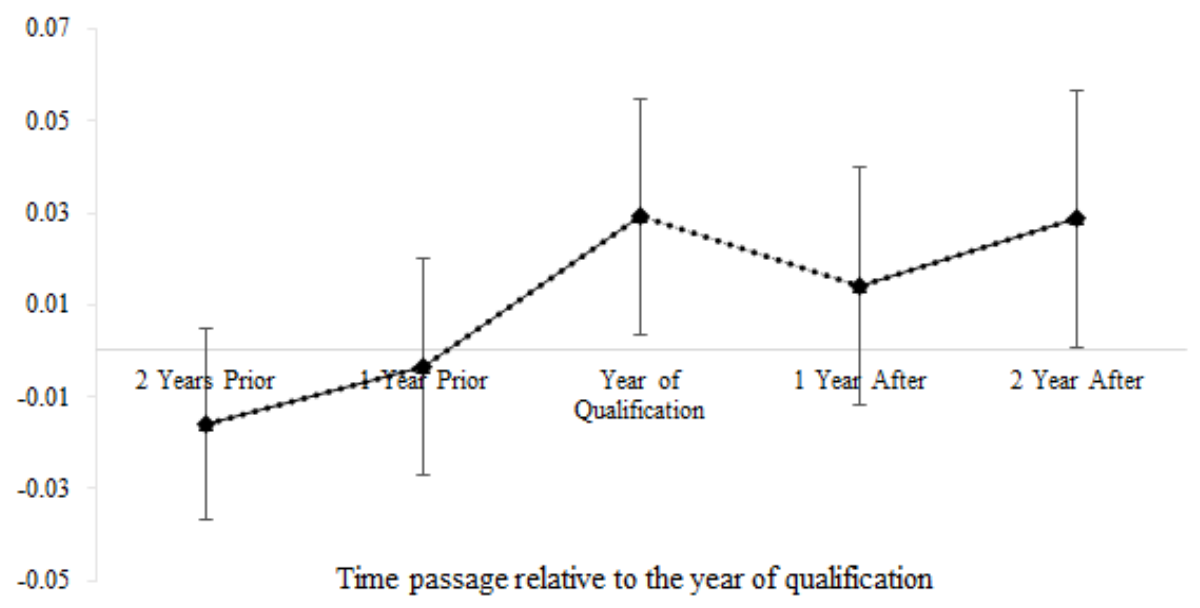

Notes: In this figure, we plot the difference in the investment rate between the treated and the control groups from 2-years prior to the reform to 2-years after the reform. We control for firm-level characteristics including the growth rate of turnover, the growth rate of total assets, lagged profitability, and the marginal tax rate while estimating differences in investment rate. Each dot stands for the point estimate, and the vertical bar stands for the $95 \%$ confidence interval.

Figure 2: Average gross investment rate for December and non-December firms

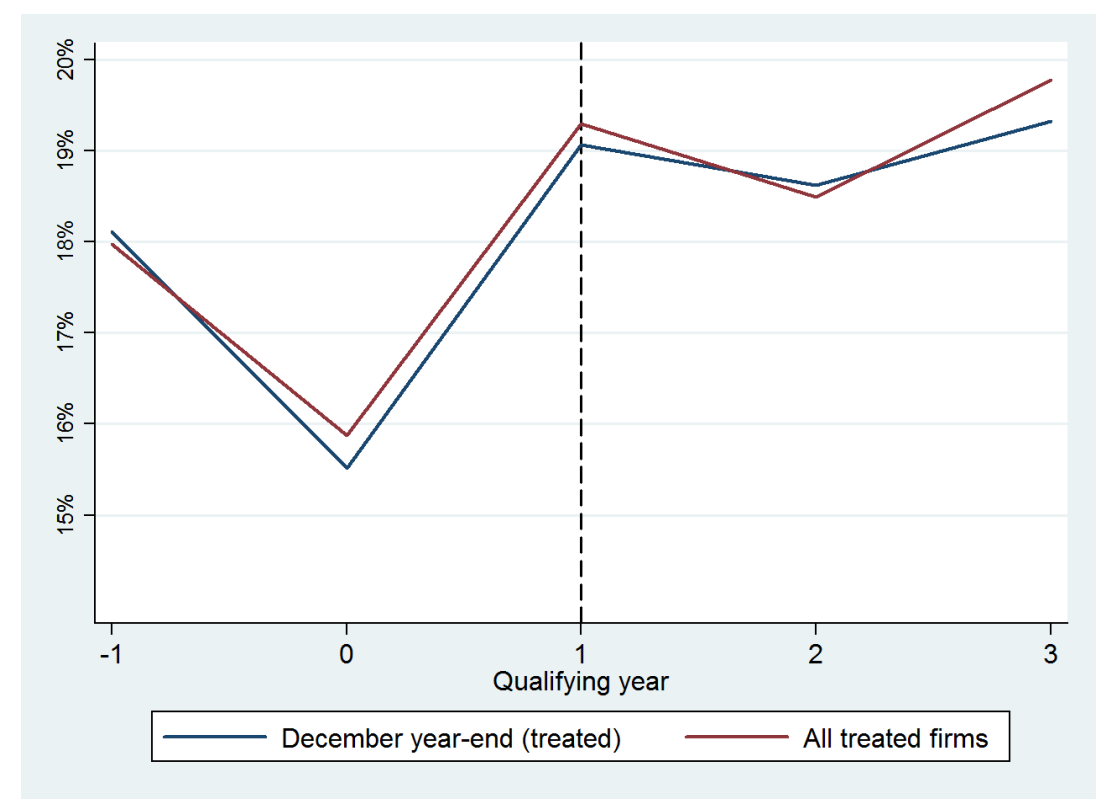

Notes: We plot in this figure the average gross investment rate for treated companies with accounting year-end in each December, and that for the rest of treated companies. We conduct a t-test of the hypothesis that the mean investment rate of treated December firms is the same as the mean investment rate of treated non-December firms in Year 0. We cannot reject the null as t-test statistic is 0.572 with $\operatorname{Pr}(|T|>|t|)=0.567$. We cannot reject the hypothesis that the mean investment rates of the two groups are the same in Year 1 as the t-test statistic is 0.292 with $\operatorname{Pr}(|T|>|t|)=$ 0.770 . 
Figure 3A: Distribution of turnover around the old threshold (between $£ 10 \mathrm{~m}$ and $£ 12 \mathrm{~m}$ )

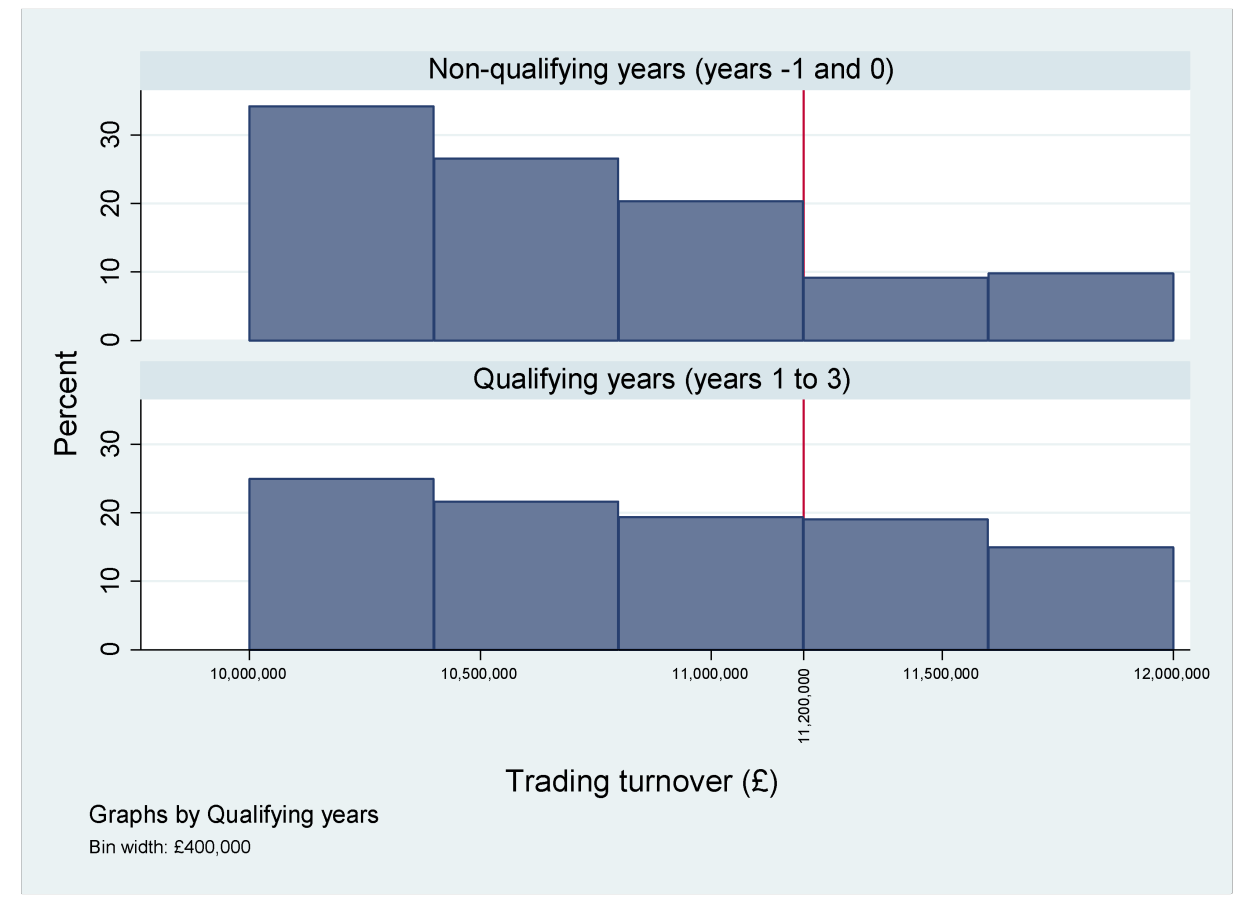

Figure 3B: Distribution of turnover around the new threshold (between $£ 20 \mathrm{~m}$ and £24m)

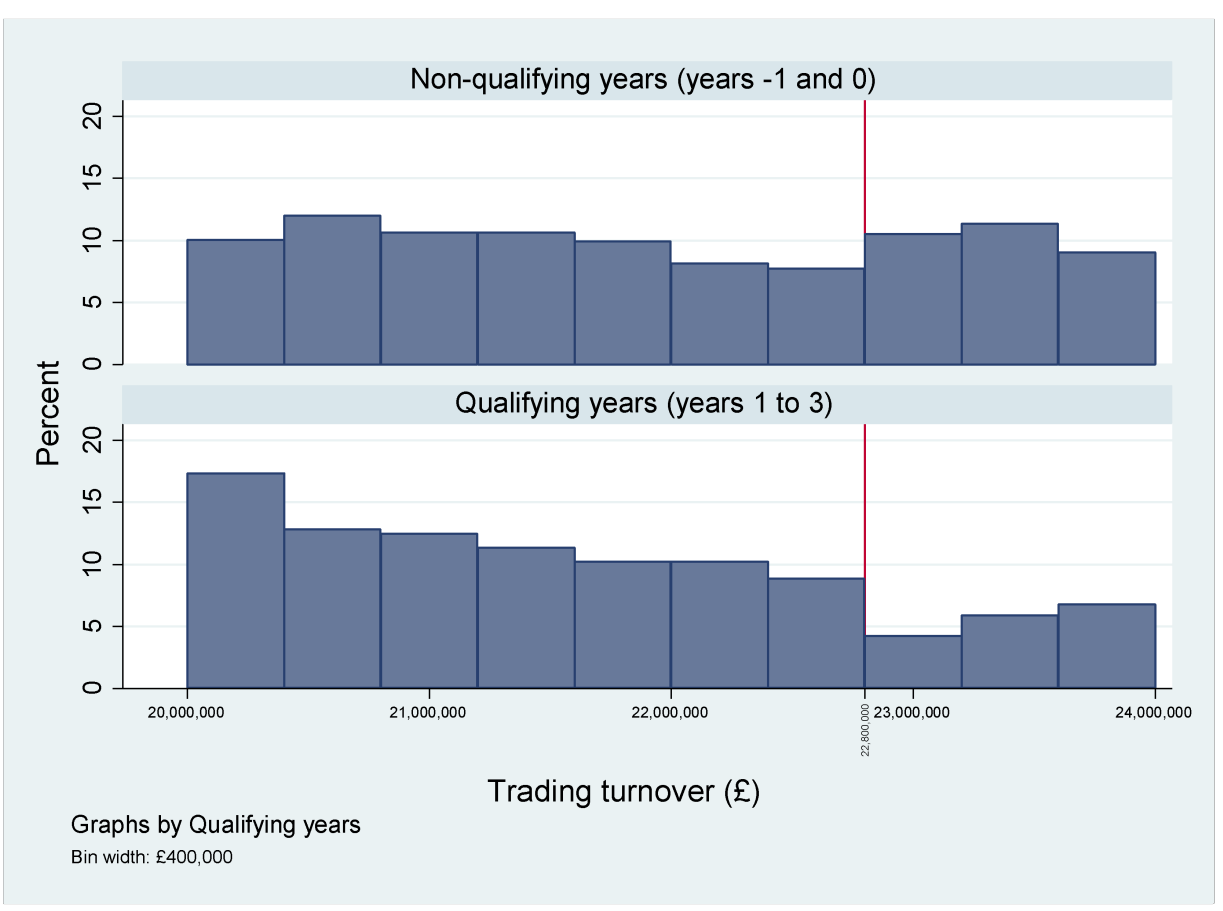




\section{Appendix A: The value of the first-year capital al- lowances}

Let $A$ denote the present value of the tax saving due to capital allowances for a unit increase in investment. $\tau$ is the marginal corporate tax rate. $r$ is the interest rate which we assume is $7 \%$. Before the reform, the rate of tax depreciation is $d=0.25$. The present value of FYAs before the reform can be expressed as:

$$
A=\tau d\left\{1+\frac{1-d}{1+r}+\left(\frac{1-d}{1+r}\right)^{2}+\left(\frac{1-d}{1+r}\right)^{3}+\ldots\right\}=\frac{\tau d(1+r)}{(r+d)}=0.8359 \tau
$$

In the case in which the asset receives an allowance of $f=40 \%$ in the first year, and then subsequently $d$ on a declining balance basis, then

$$
\begin{aligned}
A^{\prime} & =\tau f+\frac{\tau d(1-f)}{(1+r)}\left\{1+\frac{1-d}{1+r}+\left(\frac{1-d}{1+r}\right)^{2}+\left(\frac{1-d}{1+r}\right)^{3}+\ldots\right\} \\
& =\tau f+\frac{\tau d(1-f)}{(r+d)}=0.8688 \tau
\end{aligned}
$$

Thus, we have $d A / A=0.0329 \tau / 0.8359 \tau \approx 0.039$. In words, FYAs increase the present value of the capital allowances for a unit investment by around $3.9 \%$. If we assume the marginal corporate tax rate is $32.75 \%$, FYAs should lower the net-of-tax cost of a unit investment, $1-A$, by around $1.5 \%(d(1-A) /(1-A)=0.0329 \times$ $0.3275 /(1-0.8359 \times 0.3275) \approx 1.5 \%)$. 


\section{Appendix B: Sample construction and variable def- initions}

Table B1: Building the sample

\begin{tabular}{lcc}
\hline \hline & $(1)$ & $(2)$ \\
Steps & Observations & Companies \\
\hline Firms classifiable $(2002 / 03-2006 / 07)$ & $3,045,890$ & 452,196 \\
Drop if fixed assets zero or negative & $(158,051)$ & \\
Remaining & $2,887,839$ & 448,076 \\
Drop if only observations before or only after reform & $(629,764)$ & \\
Remaining & $2,258,075$ & 332,655 \\
Drop if only one observation before or after reform & $(917,514)$ & \\
Remaining & $1,340,561$ & 190,293 \\
Drop if firms changes month of end of accounts & $(61,689)$ & \\
Remaining & $1,278,872$ & 181,333 \\
Drop always-small firms & $(1,238,927)$ & \\
Remaining & 39,945 & 5,713 \\
Drop if less than 5 observations between Year -1 and 3 & $(3,378)$ & \\
Remaining & 36,567 & 5,133 \\
Drop outliers and require a balanced sample & $(12,552)$ & \\
Remaining & 24,015 & 4,803 \\
-Treated & 4,530 & 906 \\
-Never qualified & 12,835 & 2,567 \\
-Always median & 6,650 & 1,330 \\
\hline
\end{tabular}

Notes: The sample drops from 1,278,872 observations to 39,945 observations when we drop always-small firms. Always-small firms cannot be used in our quasi experimental setting because they underwent different changes in their capital allowances regime (see Table 1) and for this reason, they cannot be used as a control group. This reduction in sample size reflects that the majority of companies in the UK are small. In the universe of UK tax returns, 96 per cent of the observations could be classified as referring to a small company as they report turnover below the threshold for qualifying as a small enterprises (5.6 million) while 99 per cent report turnover below the threshold for medium enterprises (22.8 million).

Table B2: Variable definitions

\begin{tabular}{|c|c|c|c|}
\hline & & Box in tax return & FAME line \\
\hline Gross investment rate & $\begin{array}{l}\text { Qualified capital expenditures in year } t / \\
\text { fixed assets in year } t-1\end{array}$ & $118 \& 121$ & 37 \\
\hline Growth rate of turnover & Annual growth rate of trading turnover & 1 & \\
\hline Profitability & $\begin{array}{l}\text { Taxable income in year } t / \\
\text { Total assets in year } t\end{array}$ & 37 & 70 \\
\hline Marginal tax rate & $\begin{array}{l}\text { Calculated based on firms' taxable income } \\
\text { and the UK corporate tax rate schedule }\end{array}$ & 37 & \\
\hline Growth rate of total assets & Annual growth rate of total assets & & 70 \\
\hline Cash flow & $\begin{array}{l}\text { (Profit and loss after tax in year } t+ \\
\text { Depreciation in year } t \text { )/ } \\
\text { Total assets in year } t\end{array}$ & & $\begin{array}{l}16 \\
21 \\
70\end{array}$ \\
\hline
\end{tabular}




\section{Appendix C: Randomization inference}

This Appendix illustrates the procedures for conducting randomization inference, which is one approach to address potential serial correlations in difference-in-differences estimations (Bertrand et al., 2004; Chetty et al., 2009). We first randomly reassign the treatment and control status to firms in the balanced panel without replacement. We then estimate $\beta_{3}$ based on column (1) of Table 6 where we do not include any control variables, and column (5) of Table 6 where we control for firm-level characteristics and a common set of year dummies, respectively. We repeat this process $N$ times and each time we obtain an estimate of the treatment effect, $\widehat{\beta}_{3}$. These estimates form an empirical distribution of $\beta_{3}$ which allows us to compute a $\mathrm{p}$-value that is immune to serial correlation. The point estimate from column (1) of Tabe 6 is 0.021 , and that from (5) is 0.025 . Let $C$ equal to the number of $\widehat{\beta}_{3}$ if $\widehat{\beta}_{3}$ is larger than the corresponding point estimate in the baseline estimations. The randomization approach generates a p-value for the estimated treatment effect that is equal to $C / N$. We set $N=2000$ which is sufficiently large to obtain unbiased result. Based on the specification in column (1), we obtain a p-value of 0.005 . Based on the specification in column (5), we obtain a p-value of 0.014 , indicating that the estimated treatment effect is statistically significant at the 5 per cent level. These results are in line with findings from our baseline estimations. 


\section{Appendix D: Comparing two types of treated firms}

Table D1: Summary statistics and T test results

\begin{tabular}{|c|c|c|c|c|}
\hline & $\begin{array}{c}(1) \\
\text { Only turnover } \\
\text { threshold }\end{array}$ & $\begin{array}{c}(2) \\
\text { Both } \\
\text { thresholds }\end{array}$ & $\begin{array}{c}(3) \\
\text { Difference }\end{array}$ & $\begin{array}{c}\text { (4) } \\
\mathrm{T} \text { test statistics } \\
(\mathrm{p} \text {-value) }\end{array}$ \\
\hline Growth rate of turnover & $\begin{array}{l}-0.018 \\
(0.005)\end{array}$ & $\begin{array}{l}-0.029 \\
(0.007)\end{array}$ & 0.010 & 0.194 \\
\hline Growth rate of total assets & $\begin{array}{l}-0.045 \\
(0.016)\end{array}$ & $\begin{array}{l}-0.076 \\
(0.011)\end{array}$ & 0.031 & 0.225 \\
\hline Profitability & $\begin{array}{c}0.047 \\
(0.002)\end{array}$ & $\begin{array}{c}0.050 \\
(0.003)\end{array}$ & -0.003 & 0.451 \\
\hline Marginal tax rate & $\begin{array}{c}0.153 \\
(0.004)\end{array}$ & $\begin{array}{c}0.151 \\
(0.006)\end{array}$ & 0.002 & 0.745 \\
\hline Investment rate & $\begin{array}{c}0.170 \\
(0.009)\end{array}$ & $\begin{array}{c}0.167 \\
(0.111)\end{array}$ & 0.003 & 0.845 \\
\hline Cash flow & $\begin{array}{c}0.071 \\
(0.009)\end{array}$ & $\begin{array}{c}0.065 \\
(0.007)\end{array}$ & 0.006 & 0.659 \\
\hline Turnover & $\begin{array}{c}16,800,000 \\
(162,885)\end{array}$ & $\begin{array}{c}17,000,000 \\
(241,952)\end{array}$ & $-247,977$ & 0.399 \\
\hline Total assets & $\begin{array}{l}34,600,000 \\
(4,498,662)\end{array}$ & $\begin{array}{l}9,628,980 \\
(254,319)\end{array}$ & $24,971,000$ & 0.000 \\
\hline
\end{tabular}

Notes: We compare two types of treated firms: Column (1) provides the means and standard errors of variables for firms in the benchmark treatment group (1,235 observations), which are excluded from the alternative treatment group as defined in Section 4.3; and column (2) provides the statistics for firms in both the benchmark and the alternative treatment groups (547 observations). We focus on the pre-treatment period. Column (3) reports the differences in the mean (Column 1-Column 2). In Column (4), we report the p-value of the t test on the hypothesis that the means of each variable across the two types of treated firms are equal. 


\section{Appendix E: Other robustness checks}

Table E1: Alternative control groups and propensity score matching

\begin{tabular}{lccc}
\hline \hline Dependent var: $I_{i, t} / K_{i, t-1}$ & $\begin{array}{c}(1) \\
\text { Drop } \\
\text { top 5\% }\end{array}$ & $\begin{array}{c}(2) \\
\text { Drop } \\
\text { top 50\% }\end{array}$ & $\begin{array}{c}(3) \\
\text { PSM }\end{array}$ \\
\hline$d_{i, t}^{R} \times d_{i}^{T}$ & 0.023 & 0.024 & 0.024 \\
& $(0.011)$ & $(0.013)$ & $(0.010)$ \\
Control variables & Yes & Yes & Yes \\
Sector-year FE & Yes & Yes & Yes \\
Firm FE & Yes & Yes & Yes \\
No. of firms & 3,378 & 2,387 & 3,404 \\
No. of obs. & 16,724 & 10,948 & 17,020 \\
\hline
\end{tabular}

Notes: In column (1) we drop the top $5 \%$ in terms of total assets of the companies never qualifying, in column (2) the top 50\%. The percentiles refer to the distribution of total assets of the companies never qualifying. In column (3), we use a propensity score matching (PSM). We use the kernel matching method for the PSM. To construct the propensity score, we employ a Logit model which regresses the dummy indicating the treatment group on the average pre-treatment growth rate of turnover, the natural logarithm of total assets, profitability and sector dummies. Heteroscedasticity and cluster-robust standard errors are in parentheses. The unit of clustering is the industry of the firm. 


\section{Appendix F: Non-monotonic relationship between cash flow and firm size}

Figure F1: Cash flow and quintiles of firm size

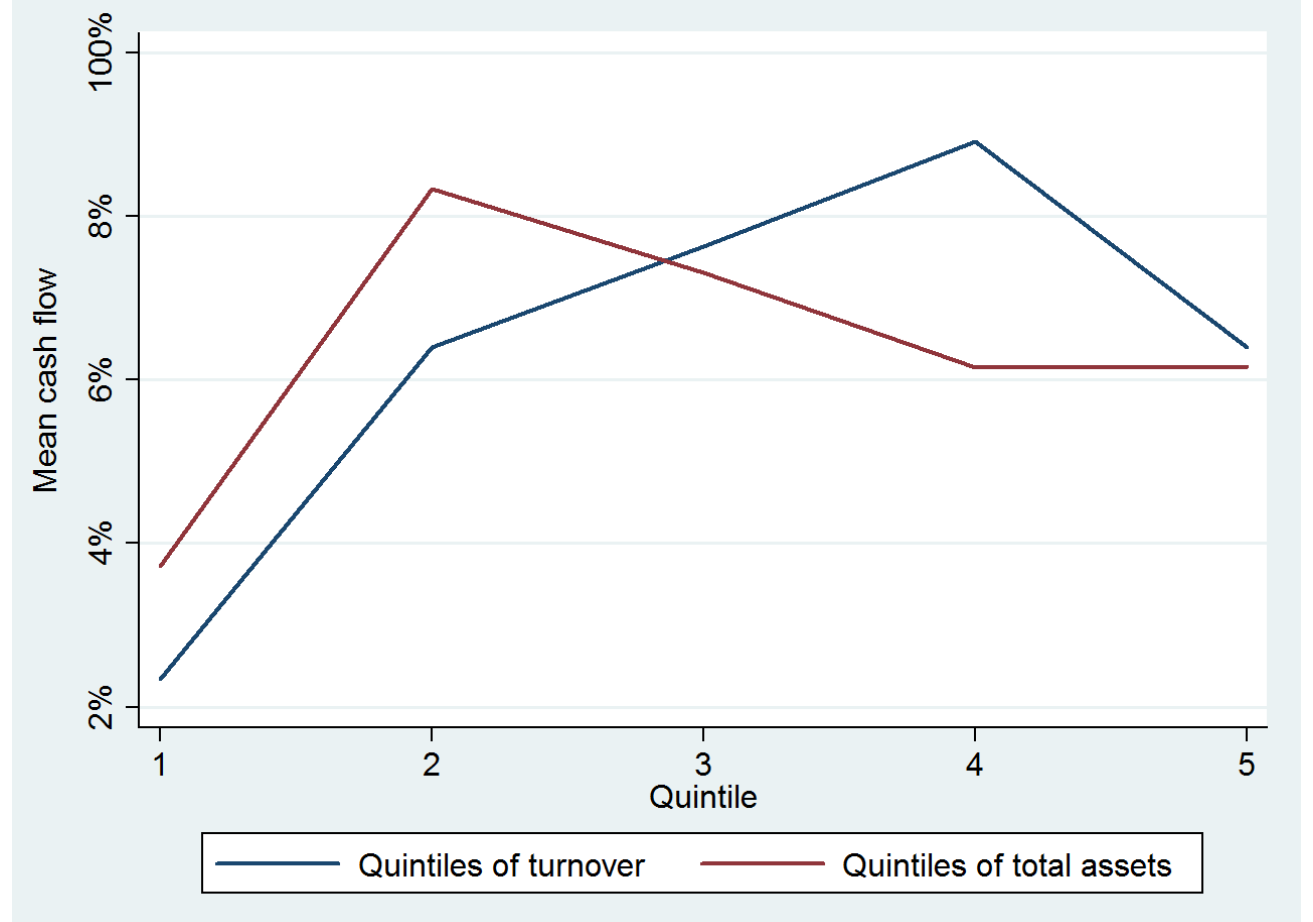

Notes: We plot the mean of cash flow, scaled by total assets, against quintiles of firm size. We use turnover and total assets as two indicators of firm size. The plot is based on the sample of treated firms. 